\title{
The PPAR-Platelet Connection: Modulators of Inflammation and Potential Cardiovascular Effects
}

\author{
S. L. Spinelli, ${ }^{1}$ J. J. O'Brien, ${ }^{2}$ S. Bancos, ${ }^{2}$ G. M. Lehmann, ${ }^{2}$ D. L. Springer, ${ }^{3}$ N. Blumberg, ${ }^{1}$ \\ C. W. Francis, ${ }^{4}$ M. B. Taubman, ${ }^{5}$ and R. P. Phipps ${ }^{2}$ \\ ${ }^{1}$ Department of Pathology and Laboratory Medicine, University of Rochester Medical Center, 601 Elmwood Avenue, \\ Box 608, Rochester, NY 14642, USA \\ ${ }^{2}$ Department of Environmental Medicine, University of Rochester Medical Center, 601 Elmwood Avenue, Rochester, \\ NY 14642, USA \\ ${ }^{3}$ Cell Biology and Biochemistry, K4-12, Biological Sciences Division Battelle, Pacific Northwest Division, 902 Battelle Blvd, \\ Richland, WA 99352, USA \\ ${ }^{4}$ MঊD-Hematology/Oncology, University of Rochester Medical Center, 601 Elmwood Avenue, \\ Rochester, NY 14642, USA \\ ${ }^{5}$ Department of Medicine, MઐD-Cardiology Unit, University of Rochester Medical Center, 601 Elmwood Avenue, \\ Box 679-ccmc, Rochester, NY 14642, USA
}

Correspondence should be addressed to R. P. Phipps, richard_phipps@urmc.rochester.edu

Received 14 August 2007; Accepted 6 November 2007

Recommended by Brian N. Finck

\begin{abstract}
Historically, platelets were viewed as simple anucleate cells responsible for initiating thrombosis and maintaining hemostasis, but clearly they are also key mediators of inflammation and immune cell activation. An emerging body of evidence links platelet function and thrombosis to vascular inflammation. Peroxisome proliferator-activated receptors (PPARs) play a major role in modulating inflammation and, interestingly, PPARs (PPAR $\beta / \delta$ and PPAR $\gamma$ ) were recently identified in platelets. Additionally, PPAR agonists attenuate platelet activation; an important discovery for two reasons. First, activated platelets are formidable antagonists that initiate and prolong a cascade of events that contribute to cardiovascular disease (CVD) progression. Dampening platelet release of proinflammatory mediators, including CD40 ligand (CD40L, CD154), is essential to hinder this cascade. Second, understanding the biologic importance of platelet PPARs and the mechanism(s) by which PPARs regulate platelet activation will be imperative in designing therapeutic strategies lacking the deleterious or unwanted side effects of current treatment options.
\end{abstract}

Copyright $\odot 2008$ S. L. Spinelli et al. This is an open access article distributed under the Creative Commons Attribution License, which permits unrestricted use, distribution, and reproduction in any medium, provided the original work is properly cited.

\section{INTRODUCTION}

Cardiovascular disease (CVD) is the leading cause of morbidity and mortality world-wide. In part, this is due to social and economic changes that lead to atherosclerosis, obesity, hypertension, dyslipidemia, and type 2 diabetes mellitus (T2DM) [1-5]. Life-style factors such as exercise, healthy diet, and avoidance of smoking are crucial to prevent disease or reduce cardiovascular risk factors. While it is important to educate individuals about healthy life-style decisions, it is also imperative to develop therapeutic strategies to attenuate the chronic inflammatory pathways linked to vascular disease [4-6]. Recently, platelets have been implicated as key contributors to the chronic inflammation that leads to CVD [5].
While platelets are essential for hemostatic regulation, new studies reveal an expanded role for platelets in thrombosis, immune cell activation, and inflammatory processes creating an obvious link between thrombosis and vascular inflammation. Platelet hyperactivity is implicated in a variety of conditions including atherosclerosis, peripheral arterial disease (PAD), T2DM, and inflammatory bowel disease (IBD) [7-10]. Although activated platelets release many proinflammatory mediators such as CD40 ligand (CD40L, CD154) and thromboxane $\mathrm{A}_{2}\left(\mathrm{TXA}_{2}\right)$, they also release membrane vesicles and platelet microparticles (PMPs), which influence the activities of other cell types both regionally and systemically. Since PMPs contain proteins important for both hemostasis and inflammation, they may amplify or sustain 


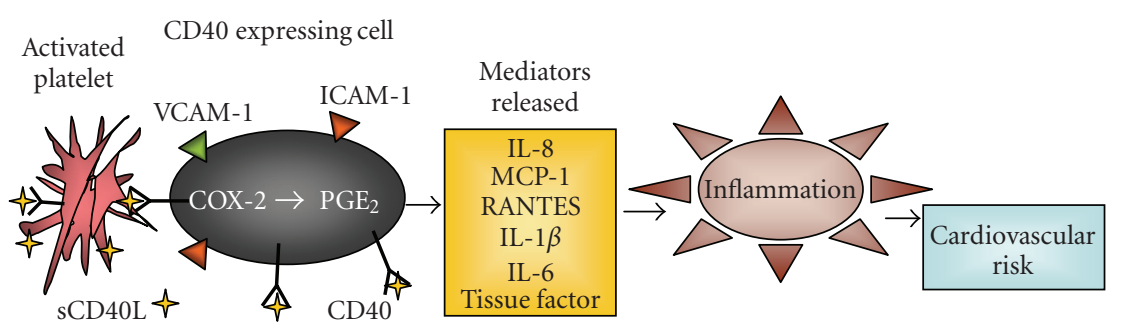

FIGURE 1: Platelets promote inflammation. CD40 expressing cells, such as endothelial cells or fibroblasts, can be activated by platelet-derived CD40L. CD40 signaling upregulates bioactive mediators in these cells; therefore, potentiating inflammation and increasing the risk for CVD.

inflammation and thrombosis contributing to a chronic inflammatory state. Moreover, higher than normal levels of platelet-released microparticles are present in individuals with atherosclerosis, T2DM, stroke, and PAD [9, 11-13].

Proteomic studies are beginning to reveal the remarkable diversity of platelet proteins and have identified proteins not known to be expressed in or released from platelets [14-16]. While lacking a nucleus, platelets contain transcription factors, notably the peroxisome proliferator-activated receptors (PPARS). PPARs are key regulators of metabolism and inflammation, and thus are poised to play an important role in processes that govern chronic inflammatory diseases [17]. Accumulating evidence suggests that PPAR activation is beneficial in the prevention of stroke and myocardial infarction (heart attack) [17, 18]. However, other studies show that some PPAR activating drugs may increase the risk of cardiovascular events [19]. Despite the lack of definitive information on the risk and benefits of taking PPAR-targeting drugs, it is clear that PPARs remain a promising target for treating CVD and more importantly, that dampening unwanted platelet activation will reduce the risk of CVD and/or improve disease outcome.

\section{PLATELETS ARE MODULATORS OF INFLAMMATION AND THROMBOSIS}

Platelets are anuclear cells released from megakaryocytes, a hematopoietic cell that differentiates and undergoes endomitosis [20]. The platelet's composition is a product of specific packaging by the megakaryocyte and the acquisition by endocytosis of blood components. Platelets contain classical cellular organelles including mitochondria and lysosomes, a complex cytoskeleton, specific platelet granules, and an open canalicular system, a complex structure of internal membranes that serves as a conduit for the movement and release of platelet contents. Despite the lack of a nucleus, platelets contain mRNA and spliceosomal components for mRNA processing, as well as the translational machinery for protein synthesis [21-23]. The recent discovery of de novo synthesis by platelets of mRNAs, including Bcl-3, interleukin- $1 \beta$ (IL$1 \beta)$, plasminogen activator inhibitor-1 (PAI-1), and tissue factor (TF), exemplifies the complexity of platelet signaling and underscores their role as formidable players in regulating coagulant and inflammatory pathways [24-29].

Platelets contain vast stores of bioactive mediators including thromboxanes, prostaglandins, chemokines, and cy- tokines that promote clot formation and incite inflammation. Upon activation, platelets produce high levels of proinflammatory mediators such as CD40L, intercellular adhesion molecule-1 (ICAM-1), tissue factor, and C-reactive protein (CRP). These mediators enhance inflammatory responses and recruitment of immune cells. Recently, it was shown that plasma levels of soluble CD40L (sCD40L) are high at birth and remain so throughout childhood [30]. The reason for the developmental change is not yet understood. In contrast, higher than normal adult levels of sCD40L in the adult bloodstream are linked with increased risk for ischemia, stroke, and myocardial infarcts due to thrombosis $[4,31]$. Based on these studies, much interest has been generated in CD40L as a possible biomarker and major factor in the progression of CVD [32-34].

\subsection{CD40L is a major contributor to chronic inflammation}

A surprising and important finding was that CD40L, a member of the tumor necrosis factor (TNF) receptor superfamily and a key mediator of both innate and adaptive immunity $[4,5,35,36]$, is released by activated platelets $[31,33,35]$. Shortly after platelets become activated, they express CD40L on their surface which is subsequently enzymatically cleaved releasing soluble bioactive CD40L into the bloodstream. This is highly significant for the following two reasons. First, platelets contain approximately 95\% of the CD40L found in human beings, and thus are a crucial link in the regulation of the CD40/CD40L pathway, as many cells express its receptor, CD40. These cells include fibroblasts, endothelial, epithelial, monocytes, neutrophils, B cells, and dendritic cells. CD40L is found in abnormally high levels in the blood of patients with chronic inflammatory diseases such as diabetes, atherosclerosis, as well as some recipients of platelet transfusions [33, 37-40]. Disruption of CD40/CD40L pathway can blunt chronic inflammation, retard atherosclerosis, and transplant rejection $[33,35,41]$. Further, recent exciting research demonstrates that CD40L is crucial for stabilizing thrombi, for normal platelet responses to sheer stress, and for platelet activation through the RGD domain of sCD40L which binds to platelet $\alpha \mathrm{IIb} \beta 3$, a receptor critical for platelet activation and aggregation $[42,43]$. Collectively, these data strongly support the importance of CD40L as a primary agonist for platelets and is considered a prototypical mediator with roles in both hemostasis and inflammation (Figure 1 
summarizes CD40 activation by platelet CD40L). Therefore, the platelet is a crucial link in the CD40/CD40L pathway and sCD40L release alone or in combination with other proinflammatory mediators may increase the risk for cardiovascular effects promoting atherosclerosis, hypertension, and dyslipidemia to list a few.

\subsection{Platelet-released microparticles are elevated in individuals with chronic inflammatory disease}

Platelet microparticles (PMPs) are defined as microvesicle particles that measure less than $1 \mu \mathrm{m}$ in diameter [44]. Platelet agonist stimulation or high shear stress leads to the highly regulated formation and release of PMPs, which are known to regulate a broad spectrum of physiological activities [45-47]. PMPs are an important delivery and cell signaling system in both inflammatory and hemostatic processes. For example, a portion of platelet IL- $1 \beta$ is associated with PMPs and signals endothelial cells, inducing their adhesiveness for neutrophils to elicit an inflammatory response [25]. PMPs signal the expression of specific adhesion molecules and stimulate the production of cytokines and mRNA in endothelial cells and in the monocytic cell line, THP-1 [48]. Notably, a known $\alpha$-granule component and proinflammatory mediator, regulated on activation, normal T-cell expressed and secreted (RANTES) (CCL5), is delivered to sites of arterial injury and atherosclerotic endothelium via PMP to promote monocyte recruitment [49]. PMPs modulate cellto-cell interactions by increasing adhesive contacts between monocytes and endothelial cells, an important first step in vascular inflammation [50]. It is also known that plateletderived tissue factor (TF) is transferred from CD62P positive PMPs to monocytes although the procoagulant role of this particle delivery system has not been established [51]. Elevated numbers of PMPs are present in a variety of diseases including atherosclerosis and other CVDs, T2DM, and cancer $[49,51-54]$. PPARs may have a potential role in the regulation of platelet activation and release of platelet contents as will be discussed further below.

\section{PEROXISOME PROLIFERATOR-ACTIVATED RECEPTORS (PPARs) AND PLATELETS}

PPARs are ligand-activated transcription factors and members of the nuclear hormone receptor superfamily. These receptors are known to play a role in regulating metabolic risk factors for CVD, such as the vascular inflammation and thrombosis associated with atherosclerosis [55]. There are three PPAR subtypes, PPAR $\alpha$ (NR1C1), PPAR $\beta / \delta$ (NUC1, NR1C2), and PPAR (NR1C3), encoded by separate genes and described in several organisms including humans. PPARs are differentially expressed in a variety of tissues and are important in the regulation of lipid and carbohydrate metabolism, energy homeostasis, cellular differentiation and apoptosis, and immune and inflammatory responses [42]. PPAR $\alpha$ is highly expressed in brown adipose tissue, liver, kidney, heart, and skeletal muscles [61]. PPAR $\beta / \delta$ has a broad tissue distribution with highest expression in the kidney, gut, and heart $[42,62]$. PPAR $\gamma$ is abundant in adipose tissue, colon, retina, and in cells of the immune system [58]. Important for this discussion are $\operatorname{PPAR} \beta / \delta$ and PPAR $\gamma$ as they were recently found to be expressed in human platelets, a surprising result considering platelets are anucleate $[63,64]$. The impact of this discovery was exemplified upon finding that exposure to PPAR agonists attenuates platelet activation and associated inflammation $[63,64]$.

Activation of PPARs in nucleated cells occurs by optimal DNA binding to a PPAR DNA response element following ligand binding and conformational changes that facilitate heterodimerization with a second ligand-activated nuclear receptor, retinoic X receptor (RXR, 9-cis retinoic acid receptor) $[65,66]$. This heterodimer binds to a cis acting DNA element in the promoters of target genes called the peroxisome proliferator response element (PPRE) to induce or repress gene transcription in a cell- and tissue-specific manner, depending on the receptor and a combination of factors, including ligand and accessory molecule binding. The physiological functions of PPAR $\alpha$ and PPAR $\gamma$ have been relatively well characterized, whereas the function of PPAR $\beta / \delta$ is poorly understood. A summary of the PPAR subtypes and their potential roles in platelets is discussed below.

\subsection{PPAR $\alpha$}

PPAR $\alpha$ activation affects transcriptional expression of approximately $80-100$ genes, the products of which regulate fatty acid oxidation, lipid metabolism, and inflammation [67]. PPAR $\alpha$ is expressed in cells of the vasculature and immune system, but has not yet been firmly identified in platelets [68]. The antiinflammatory properties of PPAR $\alpha$ are of paramount interest, but there are also reports of proinflammatory effects $[69,70]$. For example, it was demonstrated that chronic activation of PPAR $\alpha$ is detrimental to cardiac recovery during reperfusion following ischemia [71]. In contrast, it is known that PPAR $\alpha$ plays an antiinflammatory role in lung fibrosis although the mechanism is not well understood $[72,73]$. It is clear that the intricacies of PPAR $\alpha$ function must be discerned to design effective and safe drug strategies. Current PPAR $\alpha$ agonists include the fibrates, which are therapeutic agents that increase transcription of high density lipoproteins (HDL) such as ApoAI and ApoAII and are effective at lowering triglyceride levels $[74,75]$. PPAR $\alpha$ agonists have also been reported to decrease weight gain, as obesity is a contributing factor in atherosclerosis [75].

\section{2. $P P A R \beta / \delta$}

$\operatorname{PPAR} \beta / \delta$ is suggested to play a role in basic cellular functions such as cellular proliferation and differentiation, and fatty acid catabolism in skeletal muscle where it is most abundant $[76,77]$. This receptor has also been implicated in the regulation of inflammation, and shown to slow plaque formation and attenuate the progression of atherosclerosis [78]. Although little is known about the function of $\operatorname{PPAR} \beta / \delta$, especially in platelets, prostacyclin $\left(\mathrm{PGI}_{2}\right)$, an important antithrombotic and endogenous platelet hormone, is reported to be a ligand for PPAR $\beta / \delta[79,80]$. Several studies have 
revealed that $\mathrm{PGI}_{2}$ synergizes with nitric oxide (NO) to inhibit platelet aggregation in response to a variety of platelet agonists including thrombin, collagen, ADP, and lysophosphatidic acid (LPA) [64, 81-86]. It was previously shown that the synergistic effects of NO and prostacyclin on inhibition of platelet response were due to the simultaneous increase of cyclic nucleotides cGMP and cAMP [81, 87, 88]. The recent discovery that $\mathrm{PPAR} \beta / \delta$ ligands and $\mathrm{NO}$ inhibit platelet aggregation via $\operatorname{PPAR} \beta / \delta$ suggests an alternative signaling mechanism is operative in platelets [64]. This is consistent with a previous study where Ali et al. demonstrated that prostacyclin mimetics exhibited antiproliferative effects that were mediated by $\operatorname{PPAR} \beta / \delta$ and not via the prostacyclin receptor in lung fibroblasts [89]. This identified $\mathrm{PPAR} \beta / \delta$ as a potential therapeutic target for the treatment of pulmonary hypertension and supports the view that platelet $\operatorname{PPAR} \beta / \delta$ may play an important role in thrombosis [64].

\subsection{PPAR $\gamma$}

PPAR $y$ is important in adipocyte differentiation, lipid storage, and glucose homeostasis, and has emerged as a key target for new antiinflammatory therapies $[6,90,91]$. There are 3 isoforms of PPAR $\gamma(\operatorname{PPAR} \gamma 1, \operatorname{PPAR} \gamma 2$, and PPAR $\gamma 3)$. All are encoded by the same gene, but are the result of differential promoter use and alternative RNA splicing [92]. PPAR $\gamma 2$ differs from PPAR $\gamma 1$ by an additional 30 amino acids at the $\mathrm{N}$-terminus. PPAR $\gamma 1$ is present in adipose tissue, human spleen, liver, intestine, kidney, and platelets, while PPAR $\gamma 2$ is abundantly expressed only in adipose tissue and liver [93]. PPAR $\gamma 3$ mRNA has been detected in mouse macrophage cells, however its function remains unknown [94].

PPAR $\gamma$ is expressed in many cell types including fibroblasts, endothelial cells, dendritic cells, macrophages, T cells, $\mathrm{B}$ cells, and most recently we identified PPAR $\gamma$ in human platelets [59, 63, 91, 95-98]. Our laboratory recently discovered that human platelets express PPAR $\gamma$ and that PPAR $\gamma$ ligands attenuate platelet release of the proinflammatory and procoagulant mediators, sCD40L and $\mathrm{TXA}_{2}$, a cyclooxygenase (COX) product that enhances platelet activation [63]. Platelets can respond to at least two natural PPAR $\gamma$ ligands: lysophosphatidic acid (LPA) which they produce, and 15d$\mathrm{PGJ}_{2}$ which has potent antiinflammatory properties and is a metabolite of $\mathrm{PGD}_{2}[91,99,100]$. Additionally, there are several synthetic ligands in development and clinical use that are specific and potent agonists for PPAR $\gamma$ including the antidiabetic thiazolidinedione drugs (TZDs) (e.g., rosiglitazone (Avandia) and pioglitazone (Actos) both in clinical use) $[91,99]$. These will be discussed in greater detail in Section 5.

Interestingly, human platelets also contain the PPAR $\gamma$ binding partner RXR, and PPAR $\gamma$ is able to bind DNA suggesting that it can form an active PPAR $\gamma / \mathrm{RXR}$ heterodimer, and thus may be capable of biologic activity within the platelet. It is therefore possible that $\operatorname{PPAR} \gamma$ agonists interact directly with platelets to alter platelet activation and hemostatic function. While PPAR $\gamma$ was first thought to be located only in the nucleus to regulate transcription, we and others have demonstrated that PPAR $\gamma$ can be found in the cytoplasm of eukaryotic cells $[91,101]$. There is in- creasing evidence suggesting that PPAR $\gamma$ binds proteins in the cytoplasm of cells separate from its transcriptional role. For example, it was recently reported that PPAR $\gamma$ ligands, via a PPAR $\gamma$-dependent mechanism, block PKC $\alpha$ translocation to the membrane attenuating inflammatory responses in monocytes/macrophages [101]. Additionally, cytoplasmic PPAR $\gamma$ can repress the transcriptional activity of the proinflammatory mediator, nuclear factor $-\kappa \mathrm{B}(\mathrm{NF}-\kappa \mathrm{B})$, preventing its translocation to the nucleus $[92,102]$. NF- $\kappa \mathrm{B}$ is involved in regulating many aspects of cellular activity, including the immune response and has a well established role in the pathological progression of chronic inflammatory diseases [103]. Interestingly, it has also been shown in platelets that the PPAR $\gamma$ binding partner, RXR, signals through the Gq-protein receptor in a ligand-dependent manner to inhibit platelet activation [104].

Intriguingly, our group has discovered that PPAR $\gamma$ is released in a PMP-associated form and some PPAR $y$ is expelled from activated platelets as a functional PPAR $\gamma / \mathrm{RXR}$ heterodimer [105]. Moreover, the released PPAR $\gamma$ is taken up by a promonocytic cell line (THP-1) [105]. Thus, it is possible that other cells also take up platelet-released PPAR $\gamma$, quickly elevating PPAR $\gamma$ levels in recipient cells. This potential transcellular mechanism for PPAR $\gamma$ would then influence the recipient cell's susceptibility to PPAR $\gamma$ ligands and may represent a novel antiinflammatory mechanism. For example, PPAR $\gamma$ and its ligands are known to reduce VCAM-1 and ICAM-1 expression, and increase nitric oxide synthase expression on endothelial cells which is important for inhibiting platelet activation [106, 107]. These expanded antiinflammatory roles for PPAR $\gamma$ provide new avenues to pursue novel drug strategies.

\section{PLATELETS AND CARDIOVASCULAR DISEASE}

Cardiovascular disease comprises a broad spectrum of illnesses, such as hypertension, dyslipidemia, and myocardial infarction and stroke that affect the heart and the blood vessels. These conditions have similar causes (obesity, smoking, diabetes, sedentary lifestyle, and age) and platelets play a complex role in CVD, triggering early events that lead to endothelial dysfunction, to progression of vascular damage, to plaque production, and to formation of thrombi that can result in myocardial infarcts and stroke.

\subsection{Metabolic syndrome}

Platelets and their PPARs play putative roles in several manifestations of the dyslipidemia-associated "metabolic syndrome" or "syndrome X," which includes hyperglycemia, insulin resistance, obesity, hypertension, and atherosclerosis [77, 108-113]. Dyslipidemia, an increasingly common consequence of a high-fat diet, is characterized by increased serum triglycerides, low levels of antiatherogenic high density lipoprotein cholesterol (HDL) and prevalence of proatherogenic low density lipoprotein particles (LDL). Considering the imbalance between pro- and antiatherogenic factors, it is not surprising that dyslipidemia is associated with a high risk of atherosclerosis in afflicted patients [77]. HDL 
protects against atherosclerosis by driving the reverse transport of cholesterol from peripheral cells to the liver for excretion $[77,113]$. The contribution of LDL particles to the development of atherosclerosis is closely connected to platelet function and may be modulated by PPARs, as described below.

\subsection{Atherosclerosis}

Atherosclerosis is a chronic inflammatory disease characterized by plaque development within the arterial intima $[5,114]$. These atherosclerotic plaques may erode or rupture over time, triggering thrombogenesis, and possible myocardial infarction or stroke $[5,115]$. Platelets are famous for their role in clot formation during the final stages of atherosclerosis, but it has become clear from studies in both humans and animal models that the early stages of plaque formation are also platelet-mediated [5, 115-120]. Atherosclerosis is initiated when inflammatory processes activate vascular endothelial cells, resulting in platelet adhesion to the arterial wall $[115,121-123]$. When platelets adhere to the endothelial surface, they are activated, causing them to release mediators that attract and activate other cell types, including neutrophils, monocytes, and bone-marrowderived progenitor cells $[5,115]$. Monocytes cross the endothelial monolayer and enter the arterial intima by extravasation [115]. There they differentiate first into macrophages, and then, into cholesterol-laden foam cells, a critical step in atherosclerotic plaque formation [77, 115, 118]. Platelets regulate the differentiation of bone-marrow-derived progenitor cells and macrophages into foam cells $[5,115,118$, $119,124]$. Studies using fluorochrome-modified LDL have shown that platelets take up LDL and store it in dense granules $[115,118]$. These platelets can then be internalized by macrophages, a critical step in foam cell differentiation and plaque formation $[115,118,125,126]$.

One platelet-derived mediator with a clear link to atherogenesis is platelet factor 4 (PF4) which both inhibits LDL degradation by the LDL receptor and promotes monocyteto-foam cell differentiation $[115,127]$. Activated platelets also release CD40L and interleukin- $1 \beta$ which further activate the vascular endothelium, causing it to produce chemoattractants and adhesion molecules that act to recruit neutrophils and monocytes into the arterial intima $[5,115,118$, 128, 129]. Matrix metalloproteinases (MMPs) are also expressed by activated platelets, monocytes, and endothelial cells in response to CD40L; these are important in foam cell generation and the physical remodeling of the normal arterial wall to an atherosclerotic plaque $[115,118,130$ 136]. Smooth muscle cell proliferation, promoted by platelet release of transforming growth factor- $\beta$, platelet-derived growth factor, and serotonin, is also critical to this process [115].

PPARs appear to play a major role in the regulation of atherogenesis by countering the inflammation-provoking action of platelet adhesion and activation [5]. In vitro incubation of platelets with PPAR $\gamma$ agonists inhibits their ability to express CD40L and to aggregate in response to thrombin $[63,137]$. Pioglitazone, a PPAR $\gamma$-specific ligand, de- creases platelet aggregation and delays arterial thrombus formation in male LDL receptor-deficient mice $[5,138]$. Other PPAR $\gamma$ ligands, including rosiglitazone and $c 9, t 11$ conjugated linoleic acid, inhibit atherosclerotic progression in this model and in the apoE $\mathrm{E}^{-/-}$mouse $[139,140]$, possibly through their ability to inhibit platelet deposition, monocyte recruitment, macrophage differentiation, LDL uptake, foam cell formation, MMP expression, and vascular smooth muscle cell migration within atherosclerotic plaques [115, $118,137,138,141,142]$. Studies in human patients with atherosclerosis have shown that certain TZD type PPAR $\gamma$ agonists reduce both platelet and endothelial cell activation, inhibit plaque progression, improve flow-mediated vasodilation, and remarkably promote regression of existing atherosclerotic plaques $[5,115,143]$. Since phagocytosis of platelets (and their internalized LDL) by macrophages is critical to foam cell formation and atherosclerotic progression, platelet-derived PPAR $\gamma$ may be of paramount importance to the antiatherosclerotic actions of these drugs $[115,118,125$, 126]. Packaging of PPAR $\gamma$ into platelets and/or its release in PMPs may be a convenient mechanism by which this transcription factor is delivered to endothelial lesions where it may act to attenuate pathological remodeling of the arterial wall. The potential benefits of PPAR signaling are not limited to atherosclerosis, but may extend to "metabolic syndrome" as a whole. Rosiglitazone therapy reduces the systemic inflammation characteristic of "metabolic syndrome," as evidenced by decreases in serum levels of IL- 6 and TNF $\alpha$ $[5,144] . \operatorname{PPAR} \beta / \delta$ ligands have been shown to ameliorate dyslipidemia in both mice and insulin-resistant obese rhesus monkeys [113, 145, 146]. Current data suggest that PPARs will prove to be premium targets for the development of drugs to combat both dyslipidemia and atherosclerosis.

\subsection{Thrombosis}

As was discussed above, endothelial dysfunction in blood vessels is one of the earliest events that contribute to disease development triggering a chain reaction, which results in formation of atherosclerotic plaques and rupture in the blood vessel walls. A major function of platelets is to "plug" these holes by changing their shape, adhering to subendothelial surfaces, secreting the contents of intracellular organelles, and aggregating to form a thrombus in response to stimuli generated in endothelia of damaged blood vessels [147]. Several mediators are involved in platelet aggregation, such as thrombin, collagen, epinephrine (exogenous to the platelet); agents such as ADP (secreted from platelet storage granules); and thromboxane $\mathrm{A}_{2}$ (synthesized by the platelets during activation) [148]. As was mentioned above, the PPAR $\gamma$ agonists rosiglitazone and pioglitazone dampened platelet release of key proinflamatory and proatherogenic mediators such as CD40L and $\mathrm{TXA}_{2}$ [63]. The PPAR $\gamma$ agonist troglitazone has also been shown to decrease platelet aggregation in response to ADP, collagen, and arachidonic acid [149]. The mechanism whereby the vascular endothelium defends against thrombus formation involves the generation of the potent vasodilator nitric oxide (NO). NO interferes with platelet aggregation and is generated from L-arginine by the enzyme 
nitric oxide synthase (NOS) which is constitutively expressed in endothelium [150]. In experiments where rats received pioglitazone, it was found that aortic cNOS and thrombomodulin expression was upregulated and thrombus formation was delayed [151]. Pioglitazone had similar effects in the human monocyte/macrophage cell line (THP-1) where dose-dependently upregulated thrombomodulin expression was seen [152]. Other PPAR $\gamma$ ligands, such as rosiglitazone, also upregulate cNOS gene expression $[153,154]$.

\subsection{Myocardial infarction and stroke}

Myocardial infarction occurs when the blood supply to the heart is interrupted causing damage and possible death of the heart tissue. One of the major causes of myocardial infarction is rupture of the atherosclerotic plaque and formation of a platelet-rich thrombus. PPAR $\gamma$ is present in heart tissue, but there is limited data about its function there. The PPAR $\gamma$ activator rosiglitazone does inhibit TNF$\alpha$ gene expression in cultured myocytes [155]. Additionally, Rosiglitazone treatment of male Lewis rats following myocardial ischemia and reperfusion injury showed a dramatic protection against myocardial infarction, and also improved cardiac function [156]. Ischemia/reperfusion injury is characterized by an inflammatory response. Activated neutrophils release a variety of cytotoxic substances, such as oxygen-derived free radicals and proteases and activated monocytes/macrophages synthesize inflammatory cytokines [157]. Activated platelets can upregulate these responses in neutrophils and monocytes/macrophages. Together, these mediators directly participate in the amplification of an inflammatory response and, therefore, in vascular endothelial dysfunction that can lead to myocardial injury. PPAR $\gamma$ is present in monocytes/macrophages, neutrophils, and platelets, which suggests a role for PPAR $\gamma$ in negatively regulating expression of proinflammatory genes and thus, myocardial infarction [158].

Thrombus can also form in the cerebral arteries blocking the normal blood flow and causing a cerebrovascular accident (stroke). Stroke is a complex process in which several pathways are involved and successful prevention of a stroke will require drugs with pleiotropic effects. Resveratrol, found in the seeds and skin of grapes, was found to have neuroprotective effects [159] and shown to be a dual PPAR $\alpha / \gamma$ activator [18]. Experiments in a rat model have shown that pretreatment with fenofibrate and/or Wy-14643, which are $\operatorname{PPAR} \alpha$ activators, and resveratrol reduced brain infarct size after permanent focal cerebral ischemia [18]. $\operatorname{PPAR} \beta / \delta$ is found in numerous brain areas whereas PPAR $\alpha$ and PPAR $\gamma$ have a more localized expression. Inflammation and oxidative stress induce apoptotic and necrotic neuronal death and $\mathrm{NF}-\kappa \mathrm{B}$ is one of the culprits [160]. It is thought that PPARs have a neuroprotective function due to their interaction with NF- $\kappa$ B. For example, PPAR $\gamma$ binds to NF- $\kappa$ B complexes and facilitates its translocation out of the nucleus [102]. Due to their wide distribution in the neurovascular-glial compartments and their complex function, PPAR agonists offer hope in the prevention of stroke [161]. It will be of major importance to dampen platelet activity in the case of both myocar- dial infarction and stroke as ultimately, hyperactive platelets will be the major culprits in the occlusion or rupture of an artery.

\subsection{Diabetes mellitus}

Type 2 diabetes mellitus (T2DM), primarily characterized by hyperglycemia and insulin resistance, is often part of a "metabolic syndrome" which comprises hypertension, dyslipidemia, decreased fibrinolysis, and increased procoagulant factors (discussed above) [162]. Thrombocytopathia (any qualitative modification of platelets) in diabetes includes: increased platelet aggregation and adhesiveness, increased platelet number, and enhanced expression of activationdependent adhesion molecules [10]. Platelet hyperaggregability and adhesiveness in diabetes has several causes. Prostacyclin and the endothelium-derived relaxing factor nitric oxide (NO) are released by intact vascular endothelium and antagonize the effects of proaggregants so that thrombi do not form in blood vessels [163]. Platelets from diabetic patients produce less prostacyclin and $\mathrm{NO}$ and, in addition, they are less sensitive to $\mathrm{PGI}_{2}$ and nitric oxides inhibitory effects [164-166]. Insulin can target platelets directly through the platelet insulin receptor, which binds insulin and undergoes autophosphorylation [167]. Insulin reduces platelet responses to the agonists $\mathrm{ADP}$, collagen, thrombin, arachidonate, and platelet-activating factor [168]. However, in T2DM platelets express fewer insulin receptors and a decreased affinity for insulin [169]. Insulin has a direct effect on platelets and is important for maintaining platelet $\mathrm{PGI}_{2}$ sensitivity by increasing the $\mathrm{PGI}_{2}$ binding sites and as a consequence, augments cAMP response to $\mathrm{PGI}_{2}$ [170]. Numerous studies support the fact that there is an association between diabetes and oxidative stress [171]. A higher production of reactive oxygen species is thought to play an important role in diabetes complications and has been attributed to protein glycation and/or autoxidation caused by a hyperglycemic environment, and lipid peroxidation of cellular structures [172].

Oxidative defense is provided by vitamins, such as vitamin E, and by a number of enzymes, such as glutathione peroxidases. Platelets contain two glutathione peroxidases: cytosolic glutathione peroxidase (cGPx) and phospholipid hydroperoxide glutathione peroxidase (PHGPx). CGPx is involved in oxidative stress protection and in formation of eicosanoids [173, 174]. Vitamin $\mathrm{E}$ is decreased in plasma of type 1 and type 2 diabetic patients [175]. In type 2 diabetics, platelet cGPx activities were found to be lower and can lead to a relative accumulation of 12-hydroperoxyeicosatetraenoic acid (12-HpETE), the main hydroperoxide formed from arachidonic acid [175]. Thus, increase in 12HpETE could activate signal transduction pathways leading to arachidonic acid release, and amplification of platelet activation [176]. Platelet PHGPx activity was also measured for the first time in diabetic patients and was decreased in type 2 diabetics [175]. Thus, in diabetes there is an increase in free radical production and a decrease in mechanisms responsible for antioxidant defense which give rise to an environment that favors generation of radical species. 
Type 1 and 2 diabetic patients exhibit increased expression of activation-dependent adhesion molecules, such as activated $\alpha \mathrm{IIb} \beta_{3}$, lysosomal Gp53, thrombospondin, and P-selectin (CD62P) [177]. The increased expression of $\alpha \mathrm{IIb} \beta_{3}$ is consistent with the enhanced fibrinogen binding and aggregability seen in platelets from diabetic subjects [178]. Arachidonic acid metabolism, which leads to $\mathrm{TXA}_{2}$ production, is increased in diabetes and may cause platelet sensitivity $[179,180]$. Because diabetes is accompanied by CVD development, drugs that can reduce hyperglycemia and inhibit the progression of cardiovascular complications are desirable. $\operatorname{PPAR} \alpha / \gamma / \beta$ pan agonists may offer new options for treatment of diabetic complications. The blood of both type 1 and 2 diabetics shows elevated levels of CD40L [39]. PPAR $\gamma$ ligands can reduce platelet activation and thrombosis by reducing CD40L from platelets. Treatment of diabetic patients with TZD-type drugs decreased circulating CD40L blood levels [181].

\subsection{Obesity}

Obesity represents a major health threat and, in recent years, it has become clear that obesity and inflammation are linked [109-111, 182]. Obese individuals show persistent platelet activation and subsequent increased plasma levels of several proinflamatory cytokines [183]. TNF $\alpha$, adiponectin, leptin, and monocyte chemoattractant protein-1, all can originate from fat, have immunomodulating functions and show an altered profile during obesity [184]. Furthermore, $\operatorname{PPAR} \beta / \delta$ has been linked to the development of obesity. Its activation decreases adipose mass in mouse and increases fatty acid oxidation in the heart, improving muscle contraction [76]. Thus dampening platelet activation may be a means of reducing an inflammatory cascade that leads to further vascular damage and CVD.

\section{PPAR AGONISTS AS PLATELET THERAPEUTICS}

Platelets are an important pharmacological target because the thrombi developed during CVD that lead to morbidity and mortality are platelet-rich in content. Nonsteroidal antiinflammatory drugs, including aspirin, are among the most widely used drugs around the world [185]. Aspirin's primary action is to inhibit arachidonate-cyclooxygenase activity in platelets and ultimately, $\mathrm{TXA}_{2}$ release thereby, attenuating thrombus formation. Recent reports show that a subset of patients is aspirin-resistant and that aspirin may not be as effective in women. This, coupled with the fact that the cyclooxygenase pathway plays only a minor role in the action of many platelet agonists, has lead to the development of new antiplatelet therapies that complement aspirin's therapeutic effects [186-189].

There are two groups of antiplatelet agents used in conjunction with aspirin: the thienopyridines (ticlopidine and clopidogrel) and the glycoprotein (GP) IIb/IIIa $\left(\alpha \operatorname{IIb} \beta_{3}\right)$ receptor antagonists (abciximab and eptifibatide). The thienopyridines are adenosine $5^{\prime}$-diphosphate (ADP) receptor antagonists which block ADP from binding, thereby, inhibiting platelet activation, aggregation, and degranulation.

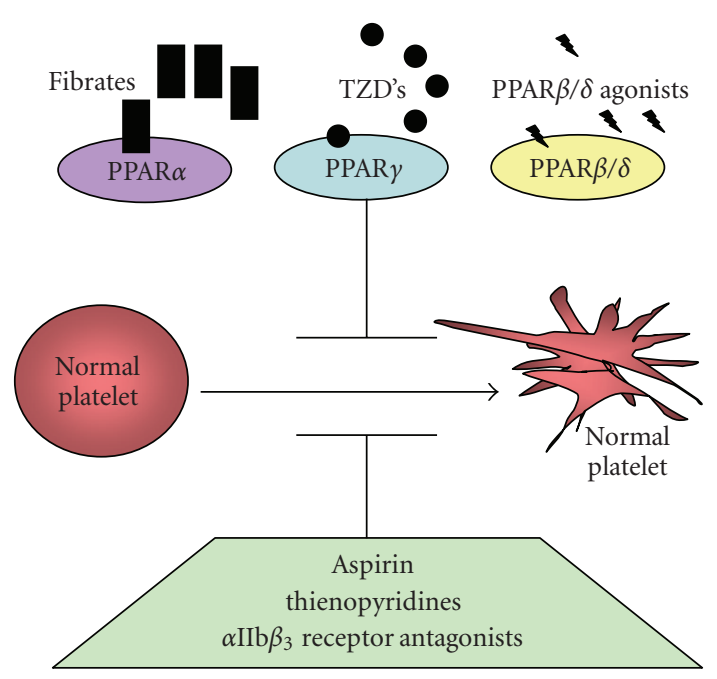

FIgure 2: Possible role of PPAR agonists in dampening inflammation and reducing cardiovascular events. PPAR agonists may reduce the risk for thrombosis. Besides playing a role in adipogenesis, lipid metabolism, and insulin sensitivity, PPARs may dampen inflammation by attenuating platelet activation.

While for the most part, thienopyridines are efficacious for reducing ischemic events, it is unclear as to whether or not clopidogrel and aspirin together are more effective than aspirin alone $[190,191]$. In rare cases, thienopyridines may cause neutropenia or thrombotic thrombocytopenia purpura $[192,193]$.

$\alpha \mathrm{IIb} \beta_{3}$ is the most important platelet membrane receptor for aggregation because it is found in high concentrations on the cell surface and binds both fibrinogen and von Willebrand factor. Blocking this receptor reduces thrombotic risks associated with acute coronary syndromes and diabetes. Unfortunately, $\alpha \mathrm{IIb} \beta_{3}$ receptor antagonists have to be administered intravenously because oral therapy causes excessive bleeding [194]. Moreover, a meta analysis of four $\alpha \operatorname{IIb} \beta_{3}$ receptor antagonist trials showed an overall increase in mortality with drug use [195].

Clearly, there is a need to develop new therapeutics that are easily administered and can dampen platelet function with fewer adverse side effects. Adding complexity to function, platelets activate and release many proinflammatory mediators and interact with not only each other, but also with many other cell-types as described in previous sections. Targeting this action of platelets could be effective in not only reducing platelet aggregation and thrombus formation, but also in attenuating chronic inflammation and, therefore, slowing disease progression.

PPAR agonists are a class of potential antiplatelet drugs that are easily administered and have the ability to impact this new physiology of platelet function. Even though PPAR agonists are primarily prescribed for the treatment of metabolic disorders, some possess the secondary benefit of inhibiting cardiovascular complications associated with hyperlipidemia and hyperglycemia. PPAR $\alpha$ agonists, fibrates, are prescribed for hyperlipidemia. They potently diminish 
blood cholesterol and triglyceride levels while raising plasma HDL levels (platelet agonists that dampen platelet activation are summarized in Figure 2).

The effect of PPAR $\alpha$ agonists on cardiovascular risk during clinical studies show mixed results. The Veterans Affair High-Density Lipoprotein Cholesterol Intervention Trial study (VA-HIT) demonstrated that the fibrate, gemfibrozil, significantly reduced nonfatal myocardial infarction and death in men with coronary cardiopathy [196]. Disappointingly, results from the recent Fenofibrate Intervention and Event Lowering in Diabetes (FIELD) trial showed no reduction in risk for the primary end-point (coronary heart disease death and nonfatatal myocardial infarction) in coronary events with fenofibrate therapy [197]. There are many explanations for these results, including the use of a low cardiovascular risk diabetic population, but it is clear that more investigation is needed to understand the clinical relevance of fibrates for treating CVD. Since platelets may lack PPAR $\alpha$, these drugs may not have a direct effect on platelet function, but may be useful in conjunction with other PPAR agonists to target multiple pathways involved in cardiovascular pathophysiology (see below).

Perhaps more promising is the use of PPAR $\gamma$ TZD agonists as antiplatelet agents. TZDs are mainly used in the treatment of T2DM because they improve insulin sensitivity by decreasing TNF- $\alpha$ and IL- 6 expression and increasing adiponectin expression [198, 199]. Troglitazone was the first PPAR $\gamma$ agonist marketed, but was withdrawn in 2000 for causing hepatotoxicity [200, 201]. Rosiglitazone and pioglitazone are the current TZDs prescribed in T2DM and have been shown to reduce the risk of myocardial infarction and stroke [202]. As was discussed in Section 3, our laboratory demonstrated that rosiglitazone attenuates CD40L surface expression and sCD40L release from thrombin-activated platelets [63]. Downregulating the CD40/CD40L system would likely provide great clinical benefit for patients with CVD. Furthermore, $15 \mathrm{~d}-\mathrm{PGJ}_{2}$ was found to attenuate $\mathrm{TXA}_{2}$ and CD40L from thrombin-activated platelets, and prevent ATP release and ADP-induced aggregation [63]. This correlates with data from a mouse model of atherosclerosis showing that pioglitazone decreases platelet activation and delays arterial thrombus formation [138]. The PROspective pioglitAzone Clinical Trial (PROACTIVE) demonstrated that pioglitazone is protective against macrovascular events in diabetic patients [203]. Rosiglitazone was also shown to reduce serum levels of matrix metalloproteinase-9 (MMP-9), implicated in atherosclerotic plaque rupture, and the proinflammatory marker CRP in patients with T2DM [204]. Conversely, some recent studies, A Diabetes Outcome Progression Trial (ADOPT) and Diabetes Reduction Assessment ramipril and Rosiglitazone Medication (DREAM), demonstrated that rosiglitazone was associated with an increase in cardiovascular risks when compared with placebo $[205,206]$. As a consequence of these recent reports that rosiglitazone may increase the incidence of myocardial infarction, a randomized, prospective, open-label trial (RECORD) was performed to assess the effects of rosiglitazone on CVD [207]. The results of this study showed a significant increase in the risk of congestive heart failure in patients taking rosiglita- zone, but no significant differences in cardiovascular-related hospitalization or death. There are many limitations to the recent studies on the cardiovascular effects of TZDs, such as small sample sizes and short trials, which clearly need to be resolved before an accurate interpretation of the data can be made. In the short term, it appears that the use of rosiglitazone and pioglitazone in patients that are not at high risk for congestive heart failure is warranted [19]. However, a better understanding of the biological effects of PPARs and the cogent design of selective therapeutics without adverse effects are imperative.

One alternative may lie in a promising new class of PPAR $\gamma$ ligands known as selective PPAR modulators (SPPARMs) that have been designed as partial PPAR $\gamma$ agonists, retaining insulin sensitization but lacking the fataccumulating properties of the classical TZD PPAR $\gamma$ ligands $[208,209]$. Given the success with SPPARMs in targeting insulin resistance, one can speculate that other properties of PPAR $\gamma$ could be targeted for partial agonist design in the future to have specific antiinflammatory activity without interference of normal thrombotic benefits or risk of potential negative cardiac effects.

There are also many other PPAR candidate drugs under investigation for the treatment of metabolic syndrome. PPAR dual agonists and PPAR pan agonists are new classes of drugs that target multiple PPAR isoforms at once to produce synergistic antidiabetic and cardioprotective effects. These drugs have the potential to improve insulin sensitivity and lower triglycerides while reducing the unwanted side effects of weight gain and edema associated with the administration of fibrates and TZDs. A novel group of dual agonists have been discovered that appear to be potent agonists of both $\operatorname{PPAR} \alpha$ and PPAR $\gamma$. These compounds known as alkoxybenzylglycines are synthetic tertiary amino acids, one of which has been demonstrated to have beneficial oral antidiabetic and antidyslipidemic efficacy in vivo [210, 211]. However, the therapeutic efficacy of dual and pan agonists in diabetesassociated cardiovascular risks is unknown.

$\operatorname{PPAR} \beta / \delta$ agonists are being developed for their ability to treat hyperlipidemia and they have the potential to exert antithrombotic effects. It was recently published that platelets express $\mathrm{PPAR} \beta / \delta$ a putative receptor for $\mathrm{PGI}_{2}$ whose activation inhibits platelet aggregation [64, 212-214]. Clearly, further studies are needed to address the effects that all PPAR agonists have on not only cardiovascular risks, but also on platelet activity. It appears that TZDs have potentially beneficial effects on overall cardiovascular risk. Understanding how targeting PPAR with pharmacological agents influences platelet biology will provide insight into the function of PPARs in platelets and help in designing drugs with better specificity and fewer adverse side effects.

\section{CONCLUSION}

The studies described herein illustrate a connection between PPARs and platelets that is significant in the pathophysiology of CVD. Platelets are emerging as potent immune and inflammatory mediators that both initiate early responses in the vasculature and elicit protracted responses that lead to 
the development of chronic inflammatory disease. Platelets contain $\mathrm{PPAR} \beta / \delta$ and PPAR $\gamma$, nuclear receptors with known antiinflammatory functions. Thus, platelets are important contributors to CVD processes and PPARs have the ability to attenuate these processes. Platelet-derived PPARs are likely to play an important role in controlling the magnitude of a platelet-driven inflammatory response. Treatment of platelets with PPAR agonists dampens the risk of thrombus formation and attenuates increased blood levels of proinflammatory mediators such as CD40L and TXA 2 . These functions of PPARs can be exploited for the development of drugs to combat such prevalent and devastating conditions as dyslipidemia, atherosclerosis, and diabetes. Understanding the specific role of platelet-derived PPARs in the process of platelet activation attenuation is essential for intelligent prevention and management of these disease states.

\section{ACKNOWLEDGMENTS}

This work is supported by T32 ES07026, ES01247, R01 HL078603, R21 HL086367, DE0113901, NHLBI-T32-66988, T32 HL07152.

\section{REFERENCES}

[1] D. L. Bhatt, P. G. Steg, E. M. Ohman, et al., "International prevalence, recognition, and treatment of cardiovascular risk factors in outpatients with atherothrombosis," Journal of the American Medical Association, vol. 295, no. 2, pp. 180-189, 2006.

[2] A. J. Lusis, "Atherosclerosis," Nature, vol. 407, no. 6801, pp. 233-241, 2000.

[3] R. P. Phipps, "Atherosclerosis: the emerging role of inflammation and the CD40-CD40 ligand system," Proceedings of the National Academy of Sciences of the United States of America, vol. 97, no. 13, pp. 6930-6932, 2000.

[4] R. P. Phipps, L. Koumas, E. Leung, S. Y. Reddy, T. Blieden, and J. Kaufman, "The CD40-CD40 ligand system: a potential therapeutic target in atherosclerosis," Current Opinion in Investigational Drugs, vol. 2, no. 6, pp. 773-777, 2001.

[5] D. M. Ray, S. L. Spinelli, J. J. O’Brien, N. Blumberg, and R. P. Phipps, "Platelets as a novel target for PPAR $\gamma$ ligands: implications for inflammation, diabetes, and cardiovascular disease," BioDrugs, vol. 20, no. 4, pp. 231-241, 2006.

[6] R. Ross, "Atherosclerosis-an inflammatory disease," The New England Journal of Medicine, vol. 340, no. 2, pp. 115126, 1999.

[7] S. Danese, C. de la Motte, A. Sturm, et al., "Platelets trigger a CD40-dependent inflammatory response in the microvasculature of inflammatory bowel disease patients," Gastroenterology, vol. 124, no. 5, pp. 1249-1264, 2003.

[8] T. Smith, G. Dhunnoo, I. Mohan, and V. Charlton-Menys, "A pilot study showing an association between platelet hyperactivity and the severity of peripheral arterial disease," Platelets, vol. 18, no. 4, pp. 245-248, 2007.

[9] K. T. Tan and G. Y. H. Lip, "The potential role of platelet microparticles in atherosclerosis," Thrombosis and Haemostasis, vol. 94, no. 3, pp. 488-492, 2005.

[10] A. I. Vinik, T. Erbas, T. S. Park, R. Nolan, and G. L. Pittenger, "Platelet dysfunction in type 2 diabetes," Diabetes Care, vol. 24, no. 8, pp. 1476-1485, 2001.
[11] Y. J. Lee, W. Jy, L. L. Horstman, et al., "Elevated platelet microparticles in transient ischemic attacks, lacunar infarcts, and multi-infarct dementias," Thrombosis Research, vol. 72, no. 4, pp. 295-304, 1993.

[12] S. Nomura, S. Uehata, S. Saito, K. Osumi, Y. Ozeki, and Y. Kimura, "Enzyme immunoassay detection of plateletderived microparticles and RANTES in acute coronary syndrome," Thrombosis and Haemostasis, vol. 89, no. 3, pp. 506512, 2003.

[13] F. Zeiger, S. Stephan, G. Hoheisel, D. Pfeiffer, C. Ruehlmann, and M. Koksch, "P-selectin expression, platelet aggregates, and platelet-derived microparticle formation are increased in peripheral arterial disease," Blood Coagulation and Fibrinolysis, vol. 11, no. 8, pp. 723-728, 2000.

[14] J. A. Coppinger, G. Cagney, S. Toomey, et al., "Characterization of the proteins released from activated platelets leads to localization of novel platelet proteins in human atherosclerotic lesions," Blood, vol. 103, no. 6, pp. 2096-2104, 2004.

[15] A. García, S. P. Watson, R. A. Dwek, and N. Zitzmann, "Applying proteomics technology to platelet research," Mass Spectrometry Reviews, vol. 24, no. 6, pp. 918-930, 2005.

[16] J. P. McRedmond, S. D. Park, D. F. Reilly, et al., "Integration of proteomics and genomics in platelets: a profile of platelet proteins and platelet-specific genes," Molecular \& Cellular Proteomics, vol. 3, no. 2, pp. 133-144, 2004.

[17] S. Kersten, B. Desvergne, and W. Wahli, "Roles of PPARs in health and disease," Nature, vol. 405, no. 6785, pp. 421-424, 2000.

[18] H. Inoue, X.-F. Jiang, T. Katayama, S. Osada, K. Umesono, and S. Namura, "Brain protection by resveratrol and fenofibrate against stroke requires peroxisome proliferatoractivated receptor $\alpha$ in mice," Neuroscience Letters, vol. 352, no. 3, pp. 203-206, 2003.

[19] “Thiazolidinediones and cardiovascular disease," The Medical Letter on Drugs and Therapeutics, vol. 49, no. 1265, pp. 57-58, 2007.

[20] S. R. Patel, J. H. Hartwig, and J. E. Italiano Jr., "The biogenesis of platelets from megakaryocyte proplatelets," Journal of Clinical Investigation, vol. 115, no. 12, pp. 3348-3354, 2005.

[21] M. M. Denis, N. D. Tolley, M. Bunting, et al., "Escaping the nuclear confines: signal-dependent pre-mRNA splicing in anucleate platelets," Cell, vol. 122, no. 3, pp. 379-391, 2005.

[22] D. V. Gnatenko, J. J. Dunn, S. R. McCorkle, D. Weissmann, P. L. Perrotta, and W. F. Bahou, "Transcript profiling of human platelets using microarray and serial analysis of gene expression," Blood, vol. 101, no. 6, pp. 2285-2293, 2003.

[23] N. Kieffer, J. Guichard, J.-P. Farcet, W. Vainchenker, and J. Breton-Gorius, "Biosynthesis of major platelet proteins in human blood platelets," European Journal of Biochemistry, vol. 164, no. 1, pp. 189-195, 1987.

[24] A. S. Weyrich, D. A. Dixon, R. Pabla, et al., "Signal-dependent translation of a regulatory protein, Bcl-3, in activated human platelets," Proceedings of the National Academy of Sciences of the United States of America, vol. 95, no. 10, pp. 5556-5561, 1998.

[25] S. Lindemann, N. D. Tolley, D. A. Dixon, et al., "Activated platelets mediate inflammatory signaling by regulated interleukin $1 \beta$ synthesis," Journal of Cell Biology, vol. 154, no. 3, pp. 485-490, 2001.

[26] H. Brogren, L. Karlsson, M. Andersson, L. Wang, D. Erlinge, and S. Jern, "Platelets synthesize large amounts of active plasminogen activator inhibitor 1," Blood, vol. 104, no. 13, pp. 3943-3948, 2004. 
[27] M. Camera, M. Frigerio, V. Toschi, et al., "Platelet activation induces cell-surface immunoreactive tissue factor expression, which is modulated differently by antiplatelet drugs," Arteriosclerosis, Thrombosis, and Vascular Biology, vol. 23, no. 9, pp. 1690-1696, 2003.

[28] H. Schwertz, N. D. Tolley, J. M. Foulks, et al., "Signaldependent splicing of tissue factor pre-mRNA modulates the thrombogenecity of human platelets," Journal of Experimental Medicine, vol. 203, no. 11, pp. 2433-2440, 2006.

[29] O. Panes, V. Matus, C. G. Sáez, T. Quiroga, J. Pereira, and D. Mezzano, "Human platelets synthesize and express functional tissue factor," Blood, vol. 109, no. 12, pp. 5242-5250, 2007.

[30] J. M. Cholette, N. Blumberg, R. P. Phipps, M. P. McDermott, K. F. Gettings, and N. P. Lerner, "Developmental changes in soluble CD40 ligand," Journal of Pediatrics. In Press.

[31] P. Libby, "Vascular biology of atherosclerosis: overview and state of the art," The American Journal of Cardiology, vol. 91, no. 3, supplement 1, pp. 3-6, 2003.

[32] P. Aukrust, F. Müller, T. Ueland, et al., "Enhanced levels of soluble and membrane-bound CD40 ligand in patients with unstable angina. Possible reflection of $\mathrm{T}$ lymphocyte and platelet involvement in the pathogenesis of acute coronary syndromes," Circulation, vol. 100, no. 6, pp. 614-620, 1999.

[33] F. Cipollone, A. Mezzetti, E. Porreca, et al., "Association between enhanced soluble CD40L and prothrombotic state in hypercholesterolemia: effects of statin therapy," Circulation, vol. 106, no. 4, pp. 399-402, 2002.

[34] C. Heeschen, S. Dimmeler, C. W. Hamm, et al., "Soluble CD40 ligand in acute coronary syndromes," The New England Journal of Medicine, vol. 348, no. 12, pp. 1104-1111, 2003.

[35] R. P. Phipps, J. Kaufman, and N. Blumberg, "Platelet derived CD154 (CD40 ligand) and febrile responses to transfusion," The Lancet, vol. 357, no. 9273, pp. 2023-2024, 2001.

[36] C. van Kooten and J. Banchereau, “CD40-CD40 ligand," Journal of Leukocyte Biology, vol. 67, no. 1, pp. 2-17, 2000.

[37] J. Kaufman, S. L. Spinelli, E. Schultz, N. Blumberg, and R. P. Phipps, "Release of biologically active CD154 during collection and storage of platelet concentrates prepared for transfusion," Journal of Thrombosis and Haemostasis, vol. 5, no. 4, pp. 788-796, 2007.

[38] C. Stumpf, C. Lehner, S. Eskafi, et al., "Enhanced levels of CD154 (CD40 ligand) on platelets in patients with chronic heart failure," European Journal of Heart Failure, vol. 5, no. 5, pp. 629-637, 2003.

[39] N. Varo, D. Vicent, P. Libby, et al., "Elevated plasma levels of the atherogenic mediator soluble CD40 ligand in diabetic patients: a novel target of thiazolidinediones," Circulation, vol. 107, no. 21, pp. 2664-2669, 2003.

[40] R. J. Noelle, "CD40 and its ligand in host defense," Immunity, vol. 4, no. 5, pp. 415-419, 1996.

[41] P. André, K. S. Srinivasa Prasad, C. V. Denis, et al., "CD40L stabilizes arterial thrombi by a $\beta_{3}$ integrin-dependent mechanism," Nature Medicine, vol. 8, no. 3, pp. 247-252, 2002.

[42] S. A. Kliewer, B. M. Forman, B. Blumberg, et al., "Differential expression and activation of a family of murine peroxisome proliferator-activated receptors," Proceedings of the National Academy of Sciences of the United States of America, vol. 91, no. 15, pp. 7355-7359, 1994.

[43] K. S. Srinivasa Prasad, P. André, M. He, M. Bao, J. Manganello, and D. R. Phillips, "Soluble CD40 ligand induces $\beta_{3}$ integrin tyrosine phosphorylation and triggers platelet activation by outside-in signaling," Proceedings of the National
Academy of Sciences of the United States of America, vol. 100, no. 21, pp. 12367-12371, 2003.

[44] L. L. Horstman, W. Jy, J. J. Jimenez, C. Bidot, and Y. S. Ahn, "New horizons in the analysis of circulating cell-derived microparticles," Keio Journal of Medicine, vol. 53, no. 4, pp. 210 230, 2004.

[45] J. Simak and M. P. Gelderman, "Cell membrane microparticles in blood and blood products: potentially pathogenic agents and diagnostic markers," Transfusion Medicine Reviews, vol. 20, no. 1, pp. 1-26, 2006.

[46] A. P. Bode, H. Sandberg, F. A. Dombrose, and B. R. Lentz, "Association of factor $\mathrm{V}$ activity with membranous vesicles released from human platelets: requirement for platelet stimulation," Thrombosis Research, vol. 39, no. 1, pp. 49-61, 1985.

[47] P. Siljander, O. Carpen, and R. Lassila, "Platelet-derived microparticles associate with fibrin during thrombosis," Blood, vol. 87, no. 11, pp. 4651-4663, 1996.

[48] S. Nomura, N. N. Tandon, T. Nakamura, J. Cone, S. Fukuhara, and J. Kambayashi, "High-shear-stress-induced activation of platelets and microparticles enhances expression of cell adhesion molecules in THP-1 and endothelial cells," Atherosclerosis, vol. 158, no. 2, pp. 277-287, 2001.

[49] S. F. Mause, P. von Hundelshausen, A. Zernecke, R. R. Koenen, and C. Weber, "Platelet microparticles: a transcellular delivery system for RANTES promoting monocyte recruitment on endothelium," Arteriosclerosis, Thrombosis, and Vascular Biology, vol. 25, no. 7, pp. 1512-1518, 2005.

[50] O. P. Barry, D. Praticò, R. C. Savani, and G. A. FitzGerald, "Modulation of monocyte-endothelial cell interactions by platelet microparticles," Journal of Clinical Investigation, vol. 102, no. 1, pp. 136-144, 1998.

[51] T. Scholz, U. Temmler, S. Krause, S. Heptinstall, and W. Lösche, "Transfer of tissue factor from platelets to monocytes: role of platelet-derived microvesicles and CD62P," Thrombosis and Haemostasis, vol. 88, no. 6, pp. 1033-1038, 2002.

[52] M. J. VanWijk, E. VanBavel, A. Sturk, and R. Nieuwland, "Microparticles in cardiovascular diseases," Cardiovascular Research, vol. 59, no. 2, pp. 277-287, 2003.

[53] M. Diamant, R. Nieuwland, R. F. Pablo, A. Sturk, J. W. A. Smit, and J. K. Radder, "Elevated numbers of tissue-factor exposing microparticles correlate with components of the metabolic syndrome in uncomplicated type 2 diabetes mellitus," Circulation, vol. 106, no. 19, pp. 2442-2447, 2002.

[54] A. Janowska-Wieczorek, M. Majka, J. Kijowski, et al., "Platelet-derived microparticles bind to hematopoietic stem/progenitor cells and enhance their engraftment," Blood, vol. 98, no. 10, pp. 3143-3149, 2001.

[55] H. Duez, J.-C. Fruchart, and B. Staels, "PPARs in inflammation, atherosclerosis and thrombosis," Journal of Cardiovascular Risk, vol. 8, no. 4, pp. 187-194, 2001.

[56] J. Padilla, K. Kaur, S. G. Harris, and R. P. Phipps, "PPAR$\gamma$-mediated regulation of normal and malignant B lineage cells," Annals of the New York Academy of Sciences, vol. 905, pp. 97-109, 2000.

[57] I. Issemann and S. Green, "Cloning of novel members of the steroid hormone receptor superfamily," Journal of Steroid Biochemistry and Molecular Biology, vol. 40, no. 1-3, pp. 263 269, 1991.

[58] O. Braissant, F. Foufelle, C. Scotto, M. Dauça, and W. Wahli, "Differential expression of peroxisome proliferator-activated receptors (PPARs): tissue distribution of PPAR- $\alpha,-\beta$, and $-\gamma$ in the adult rat," Endocrinology, vol. 137, no. 1, pp. 354-366, 1996. 
[59] S. G. Harris and R. P. Phipps, "The nuclear receptor PPAR $\gamma$ is expressed by mouse T lymphocytes and PPAR $\gamma$ agonists induce apoptosis," European Journal of Immunology, vol. 31, no. 4, pp. 1098-1105, 2001.

[60] D. M. Ray, S. H. Bernstein, and R. P. Phipps, "Human multiple myeloma cells express peroxisome proliferator-activated receptor $\gamma$ and undergo apoptosis upon exposure to PPAR $\gamma$ ligands," Clinical Immunology, vol. 113, no. 2, pp. 203-213, 2004.

[61] D. Auboeuf, J. Rieusset, L. Fajas, et al., "Tissue distribution and quantification of the expression of mRNAs of peroxisome proliferator-activated receptors and liver $\mathrm{X}$ receptor$\alpha$ in humans: no alteration in adipose tissue of obese and NIDDM patients," Diabetes, vol. 46, no. 8, pp. 1319-1327, 1997.

[62] U. Seedorf and J. Aberle, "Emerging roles of $\operatorname{PPAR} \delta$ in metabolism," Biochimica et Biophysica Acta, vol. 1771, no. 9, pp. 1125-1131, 2007.

[63] F. Akbiyik, D. M. Ray, K. F. Gettings, N. Blumberg, C. W. Francis, and R. P. Phipps, "Human bone marrow megakaryocytes and platelets express PPAR $\gamma$, and PPAR $\gamma$ agonists blunt platelet release of CD40 ligand and thromboxanes," Blood, vol. 104, no. 5, pp. 1361-1368, 2004.

[64] F. Y. Ali, S. J. Davidson, L. A. Moraes, et al., "Role of nuclear receptor signaling in platelets: antithrombotic effects of PPAR $\beta$," The FASEB Journal, vol. 20, no. 2, pp. 326-328, 2006.

[65] S. A. Kliewer, K. Umesono, D. J. Noonan, R. A. Heyman, and R. M. Evans, "Convergence of 9-cis retinoic acid and peroxisome proliferator signalling pathways through heterodimer formation of their receptors," Nature, vol. 358, no. 6389, pp. 771-774, 1992.

[66] A. I. Shulman and D. J. Mangelsdorf, "Retinoid X receptor heterodimers in the metabolic syndrome," The New England Journal of Medicine, vol. 353, no. 6, pp. 604-615, 2005.

[67] J. Plutzky, "Inflammation in atherosclerosis and diabetes mellitus," Reviews in Endocrine and Metabolic Disorders, vol. 5, no. 3, pp. 255-259, 2004.

[68] N. Marx, H. Duez, J.-C. Fruchart, and B. Staels, "Peroxisome proliferator-activated receptors and atherogenesis: regulators of gene expression in vascular cells," Circulation Research, vol. 94, no. 9, pp. 1168-1178, 2004.

[69] G. Rizzo and S. Fiorucci, "PPARs and other nuclear receptors in inflammation," Current Opinion in Pharmacology, vol. 6, no. 4, pp. 421-427, 2006.

[70] T. Sher, H. F. Yi, O. W. McBride, and F. J. Gonzalez, "cDNA cloning, chromosomal mapping, and functional characterization of the human peroxisome proliferator activated receptor," Biochemistry, vol. 32, no. 21, pp. 5598-5604, 1993.

[71] N. Sambandam, D. Morabito, C. Wagg, B. N. Finck, D. P. Kelly, and G. D. Lopaschuk, "Chronic activation of PPAR $\alpha$ is detrimental to cardiac recovery after ischemia," American Journal of Physiology, vol. 290, no. 1, pp. H87-H95, 2006.

[72] T. H. Thatcher, P. J. Sime, and R. K. Barth, "Sensitivity to bleomycin-induced lung injury is not moderated by an antigen-limited T-cell repertoire," Experimental Lung Research, vol. 31, no. 7, pp. 685-700, 2005.

[73] H. F. Lakatos, T. H. Thatcher, R. M. Kottmann, T. M. Garcia, R. P. Phipps, and P. J. Sime, "The role of PPARs in lung fibrosis," PPAR Research, vol. 2007, Article ID 71323, 10 pages, 2007.

[74] J. Auwerx, K. Schoonjans, J.-C. Fruchart, and B. Staels, "Regulation of triglyceride metabolism by PPARs: fibrates and thi- azolidinediones have distinct effects," Journal of atherosclerosis and thrombosis, vol. 3, no. 2, pp. 81-89, 1996.

[75] J. D. Brown and J. Plutzky, "Peroxisome proliferatoractivated receptors as transcriptional nodal points and therapeutic targets," Circulation, vol. 115, no. 4, pp. 518-533, 2007.

[76] Y.-X. Wang, C.-H. Lee, S. Tiep, et al., "Peroxisomeproliferator-activated receptor $\delta$ activates fat metabolism to prevent obesity," Cell, vol. 113, no. 2, pp. 159-170, 2003.

[77] G. D. Barish, V. A. Narkar, and R. M. Evans, "PPAR $\delta$ : a dagger in the heart of the metabolic syndrome," Journal of Clinical Investigation, vol. 116, no. 3, pp. 590-597, 2006.

[78] C.-H. Lee, A. Chawla, N. Urbiztondo, D. Liao, W. A. Boisvert, and R. M. Evans, "Transcriptional repression of atherogenic inflammation: modulation by PPAR $\delta$," Science, vol. 302, no. 5644, pp. 453-457, 2003.

[79] H. Lim and S. K. Dey, "Minireview: a novel pathway of prostacyclin signaling-hanging out with nuclear receptors," Endocrinology, vol. 143, no. 9, pp. 3207-3210, 2002.

[80] B. M. Forman, J. Chen, and R. M. Evans, "Hypolipidemic drugs, polyunsaturated fatty acids, and eicosanoids are ligands for peroxisome proliferator-activated receptors $\alpha$ and $\delta$," Proceedings of the National Academy of Sciences of the United States of America, vol. 94, no. 9, pp. 4312-4317, 1997.

[81] G. Anfossi, P. Massucco, E. Mularoni, F. Cavalot, L. Mattiello, and M. Trovati, "Organic nitrates and compounds that increase intraplatelet cyclic guanosine monophosphate (cGMP) levels enhance the antiaggregating effects of the stable prostacyclin analogue iloprost," Prostaglandins Leukotrienes and Essential Fatty Acids, vol. 49, no. 5, pp. 839845, 1993.

[82] R. J. Gryglewski, "Interactions between nitric oxide and prostacyclin," Seminars in Thrombosis and Hemostasis, vol. 19, no. 2, pp. 158-166, 1993.

[83] P. S. Macdonald, M. A. Read, and G. J. Dusting, "Synergistic inhibition of platelet aggregation by endothelium-derived relaxing factor and prostacyclin," Thrombosis Research, vol. 49, no. 5, pp. 437-449, 1988.

[84] M. W. Radomski, R. M. Palmer, and S. Moncada, "The antiaggregating properties of vascular endothelium: interactions between prostacyclin and nitric oxide," British Journal of Pharmacology, vol. 92, no. 3, pp. 639-646, 1987.

[85] M. Spiecker, H. Darius, and J. Meyer, "Synergistic platelet antiaggregatory effects of the adenylate cyclase activator iloprost and the guanylate cyclase activating agent SIN-1 in vivo," Thrombosis Research, vol. 70, no. 5, pp. 405-415, 1993.

[86] P. S. Lidbury, E. Antunes, G. de Nucci, and J. R. Vane, "Interactions of iloprost and sodium nitroprusside on vascular smooth muscle and platelet aggregation," British Journal of Pharmacology, vol. 98, no. 4, pp. 1275-1280, 1989.

[87] R. Katzenschlager, K. Weiss, W. Rogatti, B. A. Peskar, and H. Sinzinger, "Synergism between PGE $_{1}$-metabolites $(13,14$ dihydro-prostaglandin $\mathrm{E}_{1}$, 15-keto prostaglandin $\mathrm{E}_{1}, 15$ keto-13,14-Dihydro-prostaglandin $\mathrm{E}_{1}$ ) and nitric oxide (NO) on platelet aggregation," Prostaglandins Leukotrienes and Essential Fatty Acids, vol. 45, no. 3, pp. 207-210, 1992.

[88] R. Katzenschlager, K. Weiss, W. Rogatti, M. Stelzeneder, and H. Sinzinger, "Interaction between prostaglandin $\mathrm{E}_{1}$ and nitric oxide (NO)," Thrombosis Research, vol. 62, no. 4, pp. 299304, 1991.

[89] F. Y. Ali, K. Egan, G. A. FitzGerald, et al., "Role of prostacyclin versus peroxisome proliferator-activated receptor $\beta$ receptors in prostacyclin sensing by lung fibroblasts," American Journal 
of Respiratory Cell and Molecular Biology, vol. 34, no. 2, pp. 242-246, 2006.

[90] T. M. Willson, P. J. Brown, D. D. Sternbach, and B. R. Henke, "The PPARs: from orphan receptors to drug discovery," Journal of Medicinal Chemistry, vol. 43, no. 4, pp. 527-550, 2000.

[91] J. Padilla, E. Leung, and R. P. Phipps, "Human B lymphocytes and B lymphomas express PPAR- $\gamma$ and are killed by PPAR$\gamma$ agonists," Clinical Immunology, vol. 103, no. 1, pp. 22-33, 2002.

[92] D. Kelly, J. I. Campbell, T. P. King, et al., "Commensal anaerobic gut bacteria attenuate inflammation by regulating nuclear-cytoplasmic shutting of PPAR- $\gamma$ and ReIA," Nature Immunology, vol. 5, no. 1, pp. 104-112, 2004.

[93] Y. Zhu, C. Qi, J. R. Korenberg, et al., "Structural organization of mouse peroxisome proliferator-activated receptor $\gamma$ $(\mathrm{mPPAR} \gamma)$ gene: alternative promoter use and different splicing yield two mPPAR $\gamma$ isoforms," Proceedings of the National Academy of Sciences of the United States of America, vol. 92, no. 17, pp. 7921-7925, 1995.

[94] L. Fajas, D. Auboeuf, E. Raspé, et al., "The organization, promoter analysis, and expression of the human PPAR $\gamma$ gene," Journal of Biological Chemistry, vol. 272, no. 30, pp. 18779 18789, 1997.

[95] M. Ricote, J. Huang, L. Fajas, et al., "Expression of the peroxisome proliferator-activated receptor $\gamma(\operatorname{PPAR} \gamma)$ in human atherosclerosis and regulation in macrophages by colony stimulating factors and oxidized low density lipoprotein," Proceedings of the National Academy of Sciences of the United States of America, vol. 95, no. 13, pp. 7614-7619, 1998.

[96] K. Iijima, M. Yoshizumi, J. Ako, et al., "Expression of peroxisome proliferator-activated receptor $\gamma(\operatorname{PPAR} \gamma)$ in rat aortic smooth muscle cells," Biochemical and Biophysical Research Communications, vol. 247, no. 2, pp. 353-356, 1998.

[97] A. Nencioni, F. Grünebach, A. Zobywlaski, C. Denzlinger, W. Brugger, and P. Brossart, "Dendritic cell immunogenicity is regulated by peroxisome proliferator-activated receptor $\gamma$," Journal of Immunology, vol. 169, no. 3, pp. 1228-1235, 2002.

[98] M. Ricote, A. C. Li, T. M. Willson, C. J. Kelly, and C. K. Glass, "The peroxisome proliferator-activated receptor- $\gamma$ is a negative regulator of macrophage activation," Nature, vol. 391, no. 6662, pp. 79-82, 1998.

[99] L. Michalik, B. Desvergne, and W. Wahli, "Peroxisomeproliferator-activated receptors and cancers: complex stories," Nature Reviews Cancer, vol. 4, no. 1, pp. 61-70, 2004.

[100] S. G. Harris, J. Padilla, L. Koumas, D. M. Ray, and R. P. Phipps, "Prostaglandins as modulators of immunity," Trends in Immunology, vol. 23, no. 3, pp. 144-150, 2002.

[101] A. von Knethen, M. Soller, N. Tzieply, et al., "PPAR $\gamma 1$ attenuates cytosol to membrane translocation of $\mathrm{PKC} \alpha$ to desensitize monocytes/macrophages," Journal of Cell Biology, vol. 176, no. 5, pp. 681-694, 2007.

[102] S. W. Chung, B. Y. Kang, S. H. Kim, et al., "Oxidized low density lipoprotein inhibits interleukin-12 production in lipopolysaccharide-activated mouse macrophages via direct interactions between peroxisome proliferator-activated receptor- $\gamma$ and nuclear factor- $\kappa \mathrm{B}$," Journal of Biological Chemistry, vol. 275, no. 42, pp. 32681-32687, 2000.

[103] F. Chen, V. Castranova, X. Shi, and L. M. Demers, "New insights into the role of nuclear factor- $\kappa \mathrm{B}$, a ubiquitous transcription factor in the initiation of diseases," Clinical Chemistry, vol. 45, no. 1, pp. 7-17, 1999.

[104] L. A. Moraes, K. E. Swales, J. A. Wray, et al., "Nongenomic signaling of the retinoid $\mathrm{X}$ receptor through binding and in- hibiting Gq in human platelets," Blood, vol. 109, no. 9, pp. 3741-3744, 2007.

[105] D. M. Ray, S. L. Spinelli, S. J. Pollock, et al., "Peroxisome proliferator-activated receptor $\gamma$ and the retinoid X receptor transcription factors are released from activated human platelets and are shed in microparticles," Thrombosis and Haemostasis, vol. 101, 2008.

[106] V. Pasceri, H. D. Wu, J. T. Willerson, and E. T. H. Yeh, "Modulation of vascular inflammation in vitro and in vivo by peroxisome proliferator-activated receptor- $\gamma$ activators," Circulation, vol. 101, no. 3, pp. 235-238, 2000.

[107] K. Goya, S. Sumitani, M. Otsuki, et al., "The thiazolidinedione drug troglitazone up-regulates nitric oxide synthase expression in vascular endothelial cells," Journal of Diabetes and its Complications, vol. 20, no. 5, pp. 336-342, 2006.

[108] G. Anfossi and M. Trovati, "Pathophysiology of platelet resistance to anti-aggregating agents in insulin resistance and type 2 diabetes: implications for anti-aggregating therapy," Cardiovascular and Hematological Agents in Medicinal Chemistry, vol. 4, no. 2, pp. 111-128, 2006.

[109] I. Juhan-Vague, P. E. Morange, and M.-C. Alessi, "The insulin resistance syndrome: implications for thrombosis and cardiovascular disease," Pathophysiology of Haemostasis and Thrombosis, vol. 32, no. 5-6, pp. 269-273, 2002.

[110] D. J. Schneider, "Abnormalities of coagulation, platelet function, and fibrinolysis associated with syndromes of insulin resistance," Coronary Artery Disease, vol. 16, no. 8, pp. 473476, 2005.

[111] M. Trovati and G. Anfossi, "Mechanisms involved in platelet hyperactivation and platelet-endothelium interrelationships in diabetes mellitus," Current Diabetes Reports, vol. 2, no. 4, pp. 316-322, 2002.

[112] M. Trovati and G. Anfossi, "Influence of insulin and of insulin resistance on platelet and vascular smooth muscle cell function," Journal of Diabetes and Its Complications, vol. 16, no. 1, pp. 35-40, 2002.

[113] W. R. Oliver Jr., J. L. Shenk, M. R. Snaith, et al., "A selective peroxisome proliferator-activated receptor $\delta$ agonist promotes reverse cholesterol transport," Proceedings of the $\mathrm{Na}$ tional Academy of Sciences of the United States of America, vol. 98, no. 9, pp. 5306-5311, 2001.

[114] P. Libby, P. M. Ridker, and A. Maseri, "Inflammation and atherosclerosis," Circulation, vol. 105, no. 9, pp. 1135-1143, 2002.

[115] S. Lindemann, B. Krämer, P. Seizer, and M. Gawaz, "Platelets, inflammation and atherosclerosis," Journal of Thrombosis and Haemostasis, vol. 5, supplement 1, pp. 203-211, 2007.

[116] Z. M. Dong, S. M. Chapman, A. A. Brown, P. S. Frenette, R. O. Hynes, and D. D. Wagner, "The combined role of P- and Eselectins in atherosclerosis," Journal of Clinical Investigation, vol. 102, no. 1, pp. 145-152, 1998.

[117] Y. Huo, A. Schober, S. B. Forlow, et al., "Circulating activated platelets exacerbate atherosclerosis in mice deficient in apolipoprotein E," Nature Medicine, vol. 9, no. 1, pp. 61-67, 2002.

[118] K. Daub, H. Langer, P. Seizer, et al., "Platelets induce differentiation of human $\mathrm{CD} 34^{+}$progenitor cells into foam cells and endothelial cells," The FASEB Journal, vol. 20, no. 14, pp. 2559-2561, 2006.

[119] S. Massberg, K. Brand, S. Grüner, et al., "A critical role of platelet adhesion in the initiation of atherosclerotic lesion formation," Journal of Experimental Medicine, vol. 196, no. 7, pp. 887-896, 2002. 
[120] S. Massberg, K. Schürzinger, M. Lorenz, et al., "Platelet adhesion via glycoprotein IIb integrin is critical for atheroprogression and focal cerebral ischemia: an in vivo study in mice lacking glycoprotein IIb," Circulation, vol. 112, no. 8, pp. 1180-1188, 2005.

[121] T. Bombeli, B. R. Schwartz, and J. M. Harlan, "Adhesion of activated platelets to endothelial cells: evidence for a GPIIbIIIa-dependent bridging mechanism and novel roles for endothelial intercellular adhesion molecule 1 (ICAM-1), $\alpha_{\mathrm{v}} \beta_{3}$ integrin, and GPIb $\alpha$," Journal of Experimental Medicine, vol. 187, no. 3, pp. 329-339, 1998.

[122] M. Gawaz, F.-J. Neumann, T. Dickfeld, et al., "Vitronectin receptor $\left(\alpha_{v} \beta_{3}\right)$ mediates platelet adhesion to the luminal aspect of endothelial cells: implications for reperfusion in acute myocardial infarction," Circulation, vol. 96, no. 6, pp. 1809_ 1818, 1997.

[123] M. Gawaz, F.-J. Neumann, I. Ott, A. Schiessler, and A. Schömig, "Platelet function in acute myocardial infarction treated with direct angioplasty," Circulation, vol. 93, no. 2, pp. 229-237, 1996.

[124] H. Langer, A. E. May, K. Daub, et al., "Adherent platelets recruit and induce differentiation of murine embryonic endothelial progenitor cells to mature endothelial cells in vitro," Circulation Research, vol. 98, no. 2, pp. e2-e10, 2006.

[125] D. M. Jans, W. Martinet, M. Fillet, et al., "Effect of nonsteroidal anti-inflammatory drugs on amyloid- $\beta$ formation and macrophage activation after platelet phagocytosis," Journal of Cardiovascular Pharmacology, vol. 43, no. 3, pp. 462470, 2004.

[126] G. R. Y. De Meyer, D. M. M. De Cleen, S. Cooper, et al., "Platelet phagocytosis and processing of $\beta$-amyloid precursor protein as a mechanism of macrophage activation in atherosclerosis," Circulation Research, vol. 90, no. 11, pp. 1197-1204, 2002.

[127] T. Nassar, B. S. Sachais, S. Akkawi, et al., "Platelet factor 4 enhances the binding of oxidized low-density lipoprotein to vascular wall cells," Journal of Biological Chemistry, vol. 278, no. 8, pp. 6187-6193, 2003.

[128] M. Gawaz, K. Brand, T. Dickfeld, et al., "Platelets induce alterations of chemotactic and adhesive properties of endothelial cells mediated through an interleukin-1-dependent mechanism. Implications for atherogenesis," Atherosclerosis, vol. 148, no. 1, pp. 75-85, 2000.

[129] P. von Hundelshausen, K. S. Weber, Y. Huo, et al., "RANTES deposition by platelets triggers monocyte arrest on inflamed and atherosclerotic endothelium," Circulation, vol. 103, no. 13, pp. 1772-1777, 2001.

[130] C. Fernandez-Patron, M. A. Martinez-Cuesta, E. Salas, et al., "Differential regulation of platelet aggregation by matrix metalloproteinases-9 and -2," Thrombosis and Haemostasis, vol. 82, no. 6, pp. 1730-1735, 1999.

[131] G. Sawicki, E. Salas, J. Murat, H. Miszta-Lane, and M. W. Radomski, "Release of gelatinase A during platelet activation mediates aggregation," Nature, vol. 386, no. 6625, pp. 616619, 1997.

[132] A. E. May, T. Kälsch, S. Massberg, Y. Herouy, R. Schmidt, and M. Gawaz, "Engagement of glycoprotein IIb/IIIa $\left(\alpha_{\mathrm{IIb}} \beta_{3}\right)$ on platelets upregulates CD40L and triggers CD40Ldependent matrix degradation by endothelial cells," Circulation, vol. 106, no. 16, pp. 2111-2117, 2002.

[133] S. Bellosta, D. Via, M. Canavesi, et al., "HMG-CoA reductase inhibitors reduce MMP-9 secretion by macrophages," Arteriosclerosis, Thrombosis, and Vascular Biology, vol. 18, no. 11, pp. 1671-1678, 1998.
[134] S. W. Galt, S. Lindemann, D. Medd, et al., "Differential regulation of matrix metalloproteinase- 9 by monocytes adherent to collagen and platelets," Circulation Research, vol. 89, no. 6, pp. 509-516, 2001.

[135] N. A. Turner, D. J. O’Regan, S. G. Ball, and K. E. Porter, "Simvastatin inhibits MMP-9 secretion from human saphenous vein smooth muscle cells by inhibiting the RhoA/ROCK pathway and reducing MMP-9 mRNA levels," The FASEB Journal, vol. 19, no. 7, pp. 804-806, 2005.

[136] B. Wong, W. C. Lumma, A. M. Smith, J. T. Sisko, S. D. Wright, and T.-Q. Cai, "Statins suppress THP-1 cell migration and secretion of matrix metalloproteinase 9 by inhibiting geranylgeranylation," Journal of Leukocyte Biology, vol. 69, no. 6, pp. 959-962, 2001.

[137] S. Toomey, B. Harhen, H. M. Roche, D. Fitzgerald, and O. Belton, "Profound resolution of early atherosclerosis with conjugated linoleic acid," Atherosclerosis, vol. 187, no. 1, pp. 40-49, 2006.

[138] A. C. Li, C. J. Binder, A. Gutierrez, et al., "Differential inhibition of macrophage foam-cell formation and atherosclerosis in mice by $\operatorname{PPAR} \alpha, \beta / \delta$, and $\gamma$," Journal of Clinical Investigation, vol. 114, no. 11, pp. 1564-1576, 2004.

[139] Z. Chen, S. Ishibashi, S. Perrey, et al., "Troglitazone inhibits atherosclerosis in apolipoprotein E-knockout mice: pleiotropic effects on CD36 expression and HDL," Arteriosclerosis, Thrombosis, and Vascular Biology, vol. 21, no. 3, pp. 372-377, 2001.

[140] A. C. Li, K. K. Brown, M. J. Silvestre, T. M. Willson, W. Palinski, and C. K. Glass, "Peroxisome proliferator-activated receptor $\gamma$ ligands inhibit development of atherosclerosis in LDL receptor-deficient mice," Journal of Clinical Investigation, vol. 106, no. 4, pp. 523-531, 2000.

[141] S. Cuzzocrea, B. Pisano, L. Dugo, et al., "Rosiglitazone, a ligand of the peroxisome proliferator-activated receptor- $\gamma$, reduces acute pancreatitis induced by cerulein," Intensive Care Medicine, vol. 30, no. 5, pp. 951-956, 2004.

[142] H. Shu, B. Wong, G. Zhou, et al., "Activation of PPAR $\alpha$ or $\gamma$ reduces secretion of matrix metalloproteinase 9 but not interleukin 8 from human monocytic THP-1 cells," Biochemical and Biophysical Research Communications, vol. 267, no. 1, pp. 345-349, 2000.

[143] J. S. Sidhu, D. Cowan, J. A. Tooze, and J.-C. Kaski, "Peroxisome proliferator-activated receptor- $\gamma$ agonist rosiglitazone reduces circulating platelet activity in patients without diabetes mellitus who have coronary artery disease," American Heart Journal, vol. 147, no. 6, pp. 1032-1037, 2004.

[144] F. F. Samaha, P. O. Szapary, N. Iqbal, et al., "Effects of rosiglitazone on lipids, adipokines, and inflammatory markers in nondiabetic patients with low high-density lipoprotein cholesterol and metabolic syndrome," Arteriosclerosis, Thrombosis, and Vascular Biology, vol. 26, no. 3, pp. 624-630, 2006.

[145] M. D. Leibowitz, C. Fiévet, N. Hennuyer, et al., "Activation of $\operatorname{PPAR} \delta$ alters lipid metabolism in db/db mice," FEBS Letters, vol. 473, no. 3, pp. 333-336, 2000.

[146] J. N. van der Veen, J. K. Kruit, R. Havinga, et al., "Reduced cholesterol absorption upon PPAR $\delta$ activation coincides with decreased intestinal expression of NPC1L1," Journal of Lipid Research, vol. 46, no. 3, pp. 526-534, 2005.

[147] A. Gallino, A. Haeberli, H. R. Baur, and P. W. Straub, "Fibrin formation and platelet aggregation in patients with severe coronary artery disease: relationship with the degree of myocardial ischemia," Circulation, vol. 72, no. 1, pp. 27-30, 1985. 
[148] B. Ashby, J. L. Daniel, and J. B. Smith, "Mechanisms of platelet activation and inhibition," Hematology/Oncology Clinics of North America, vol. 4, no. 1, pp. 1-26, 1990.

[149] T. Ishizuka, S. Itaya, H. Wada, et al., "Differential effect of the antidiabetic thiazolidinediones troglitazone and pioglitazone on human platelet aggregation mechanism," Diabetes, vol. 47, no. 9, pp. 1494-1500, 1998.

[150] M. Lorenz, S. Wessler, E. Follmann, et al., "A constituent of green tea, epigallocatechin-3-gallate, activates endothelial nitric oxide synthase by a phosphatidylinositol-3-OH-kinase-, cAMP-dependent protein kinase-, and Akt-dependent pathway and leads to endothelial-dependent vasorelaxation," Journal of Biological Chemistry, vol. 279, no. 7, pp. 61906195, 2004.

[151] D. Li, K. Chen, N. Sinha, et al., "The effects of PPAR- $\gamma$ ligand pioglitazone on platelet aggregation and arterial thrombus formation," Cardiovascular Research, vol. 65, no. 4, pp. 907-912, 2005.

[152] H. Kanehara, G. Tohda, K. Oida, J. Suzuki, H. Ishii, and I. Miyamori, "Thrombomodulin expression by THP-1 but not by vascular endothelial cells is upregulated by pioglitazone," Thrombosis Research, vol. 108, no. 4, pp. 227-234, 2002.

[153] D. S. Calnek, L. Mazzella, S. Roser, J. Roman, and C. M. Hart, "Peroxisome proliferator-activated receptor $\gamma$ ligands increase release of nitric oxide from endothelial cells," Arteriosclerosis, Thrombosis, and Vascular Biology, vol. 23, no. 1, pp. 52-57, 2003.

[154] D.-H. Cho, Y. J. Choi, S. A. Jo, and I. Jo, "Nitric oxide production and regulation of endothelial nitricoxide synthase phosphorylation by prolonged treatment with troglitazone: evidence for involvement of peroxisome proliferator-activated receptor (PPAR) $\gamma$-dependent and PPAR $\gamma$-independent signaling pathways," Journal of Biological Chemistry, vol. 279, no. 4, pp. 2499-2506, 2004.

[155] H. Takano, T. Nagai, M. Asakawa, et al., "Peroxisome proliferator-activated receptor activators inhibit lipopolysaccharide-induced tumor necrosis factor- $\alpha$ expression in neonatal rat cardiac myocytes," Circulation Research, vol. 87, no. 7, pp. 596-602, 2000.

[156] T.-L. Yue, J. Chen, W. Bao, et al., "In vivo myocardial protection from ischemia/reperfusion injury by the peroxisome proliferator-activated receptor- $\gamma$ agonist rosiglitazone," Circulation, vol. 104, no. 21, pp. 2588-2594, 2001.

[157] J. E. Jordan, Z.-Q. Zhao, and J. Vinten-Johansen, "The role of neutrophils in myocardial ischemia-reperfusion injury," Cardiovascular Research, vol. 43, no. 4, pp. 860-878, 1999.

[158] M. Ricote, J. T. Huang, J. S. Welch, and C. K. Glass, “The peroxisome proliferator-activated receptor $\gamma(\operatorname{PPAR} \gamma)$ as a regulator of monocyte/macrophage function," Journal of Leukocyte Biology, vol. 66, no. 5, pp. 733-739, 1999.

[159] S. S. Huang, M. C. Tsai, C. L. Chih, L. M. Hung, and S. K. Tsai, "Resveratrol reduction of infarct size in Long-Evans rats subjected to focal cerebral ischemia," Life Sciences, vol. 69, no. 9, pp. 1057-1065, 2001.

[160] D. L. Feinstein, “Therapeutic potential of peroxisome proliferator-activated receptor agonists for neurological disease," Diabetes Technology \& Therapeutics, vol. 5, no. 1, pp. 67-73, 2003.

[161] R. Bordet, T. Ouk, O. Petrault, et al., "PPAR: a new pharmacological target for neuroprotection in stroke and neurodegenerative diseases," Biochemical Society Transactions, vol. 34, part 6, pp. 1341-1346, 2006.

[162] S. Rios, "Relationship between obesity and the increased risk of major complications in non-insulin-dependent diabetes mellitus," European Journal of Clinical Investigation, vol. 28, supplement 2, pp. 14-18, 1998.

[163] R. J. Gryglewski, R. M. Botting, and J. R. Vane, "Mediators produced by the endothelial cell," Hypertension, vol. 12, no. 6, pp. 530-548, 1988.

[164] G. Anfossi, E. M. Mularoni, S. Burzacca, et al., "Platelet resistance to nitrates in obesity and obese NIDDM, and normal platelet sensitivity to both insulin and nitrates in lean NIDDM," Diabetes Care, vol. 21, no. 1, pp. 121-126, 1998.

[165] G. Anfossi, I. Russo, P. Massucco, et al., "Impaired synthesis and action of antiaggregating cyclic nucleotides in platelets from obese subjects: possible role in platelet hyperactivation in obesity," European Journal of Clinical Investigation, vol. 34, no. 7, pp. 482-489, 2004.

[166] T. Akai, K. Naka, K. Okuda, T. Takemura, and S. Fujii, “Decreased sensitivity of platelets to prostacyclin in patients with diabetes mellitus," Hormone and Metabolic Research, vol. 15, no. 11 , pp. 523-526, 1983.

[167] C. Falcon, G. Pfliegler, H. Deckmyn, and J. Vermylen, “The platelet insulin receptor: detection, partial characterizaztion, and search for a function," Biochemical and Biophysical Research Communications, vol. 157, no. 3, pp. 1190-1196, 1988.

[168] M. Trovati, G. Anfossi, F. Cavalot, P. Massucco, E. Mularoni, and G. Emanuelli, "Insulin directly reduces platelet sensitivity to aggregating agents. Studies in vitro and in vivo," Diabetes, vol. 37, no. 6, pp. 780-786, 1988.

[169] M. Udvardy, G. Pfliegler, and K. Rak, "Platelet insulin receptor determination in non-insulin dependent diabetes mellitus," Cellular and Molecular Life Sciences, vol. 41, no. 3, pp. 422-423, 1985.

[170] N. N. Kahn, H. S. Mueller, and A. K. Sinha, "Restoration by insulin of impaired prostaglandin E1/I2 receptor activity of platelets in acute ischemic heart disease," Circulation Research, vol. 68, no. 1, pp. 245-254, 1991.

[171] B. Lipinski, "Pathophysiology of oxidative stress in diabetes mellitus," Journal of Diabetes and its Complications, vol. 15, no. 4, pp. 203-210, 2001.

[172] J. V. Hunt, C. C. Smith, and S. P. Wolff, "Autoxidative glycosylation and possible involvement of peroxides and free radicals in LDL modification by glucose," Diabetes, vol. 39, no. 11, pp. 1420-1424, 1990.

[173] W. E. Lands and R. J. Kulmacz, "The regulation of the biosynthesis of prostaglandins and leukotrienes," Progress in Lipid Research, vol. 25, no. 1-4, pp. 105-109, 1986.

[174] M. Lagarde, "Metabolism of fatty acids by platelets and the functions of various metabolites in mediating platelet function," Progress in Lipid Research, vol. 27, no. 2, pp. 135-152, 1988.

[175] E. Véricel, C. Januel, M. Carreras, P. Moulin, and M. Lagarde, "Diabetic patients without vascular complications display enhanced basal platelet activation and decreased antioxidant status," Diabetes, vol. 53, no. 4, pp. 1046-1051, 2004.

[176] C. Calzada, E. Véricel, B. Mitel, L. Coulon, and M. Lagarde, "12(S)-hydroperoxy-eicosatetraenoic acid increases arachidonic acid availability in collagen-primed platelets," Journal of Lipid Research, vol. 42, no. 9, pp. 1467-1473, 2001.

[177] D. Tschoepe, U. Rauch, and B. Schwippert, "Plateletleukocyte-cross-talk in diabetes mellitus," Hormone and Metabolic Research, vol. 29, no. 12, pp. 631-635, 1997.

[178] H. Lee, R. C. Paton, P. Passa, and J. P. Caen, "Fibrinogen binding and ADP-induced aggregation in platelets from diabetic subjects," Thrombosis Research, vol. 24, no. 1-2, pp. 143-150, 1981. 
[179] P. V. Halushka, R. C. Rogers, C. B. Loadholt, and J. A. Colwell, "Increased platelet thromboxane synthesis in diabetes mellitus," Journal of Laboratory and Clinical Medicine, vol. 97, no. 1, pp. 87-96, 1981.

[180] R. K. Mayfield, P. V. Halushka, H. J. Wohltmann, et al., "Platelet function during continuous insulin infusion treatment in insulin-dependent diabetic patients," Diabetes, vol. 34, no. 11, pp. 1127-1133, 1985.

[181] N. Marx, A. Imhof, J. Froehlich, et al., "Effect of rosiglitazone treatment on soluble CD40L in patients with type 2 diabetes and coronary artery disease," Circulation, vol. 107, no. 15, pp. 1954-1957, 2003.

[182] R. Stienstra, C. Duval, M. Müller, and S. Kersten, "PPARs, obesity, and inflammation," PPAR Research, vol. 2007, Article ID 95974, 10 pages, 2007.

[183] P. Trayhurn and I. S. Wood, "Signalling role of adipose tissue: adipokines and inflammation in obesity," Biochemical Society Transactions, vol. 33, part 5, pp. 1078-1081, 2005.

[184] Y.-H. Yu and H. N. Ginsberg, "Adipocyte signaling and lipid homeostasis: sequelae of insulin-resistant adipose tissue," Circulation Research, vol. 96, no. 10, pp. 1042-1052, 2005.

[185] R. Jones, "Nonsteroidal anti-inflammatory drug prescribing: past, present, and future," The American Journal of Medicine, vol. 110, no. 1, supplement 1, pp. S4-S7, 2001.

[186] G. J. Hankey and J. W. Eikelboom, "Aspirin resistance," British Medical Journal, vol. 328, no. 7438, pp. 477-479, 2004.

[187] J. A. Cambria-Kiely and P. J. Gandhi, "Aspirin resistance and genetic polymorphisms," Journal of Thrombosis and Thrombolysis, vol. 14, no. 1, pp. 51-58, 2002.

[188] A. Szczeklik, J. Musiał, A. Undas, and M. Sanak, "Aspirin resistance," Journal of Thrombosis and Haemostasis, vol. 3, no. 8, pp. 1655-1662, 2005.

[189] D. M. Becker, J. Segal, D. Vaidya, et al., "Sex differences in platelet reactivity and response to low-dose aspirin therapy," Journal of the American Medical Association, vol. 295, no. 12, pp. 1420-1427, 2006.

[190] D. L. Bhatt, K. A. A. Fox, W. Hacke, et al., "Clopidogrel and aspirin versus aspirin alone for the prevention of atherothrombotic events," The New England Journal of Medicine, vol. 354, no. 16, pp. 1706-1717, 2006.

[191] D. L. Bhatt and E. J. Topol, "Clopidogrel added to aspirin versus aspirin alone in secondary prevention and high-risk primary prevention: rationale and design of the clopidogrel for high atherothrombotic risk and ischemic stabilization, management, and avoidance (CHARISMA) trial," American Heart Journal, vol. 148, no. 2, pp. 263-268, 2004.

[192] C. L. Bennett, J. M. Connors, J. M. Carwile, et al., "Thrombotic thrombocytopenic purpura associated with clopidogrel," The New England Journal of Medicine, vol. 342, no. 24, pp. 1773-1777, 2000.

[193] S. R. Steinhubl, W. A. Tan, J. M. Foody, and E. J. Topol, "Incidence and clinical course of thrombotic thrombocytopenic purpura due to ticlopidine following coronary stenting," Journal of the American Medical Association, vol. 281, no. 9, pp. 806-810, 1999.

[194] D. P. Chew and D. L. Bhatt, "Oral glycoprotein IIb/IIIa antagonists in coronary artery disease," Current Cardiology Reports, vol. 3, no. 1, pp. 63-71, 2001.

[195] D. P. Chew, D. L. Bhatt, S. Sapp, and E. J. Topol, "Increased mortality with oral platelet glycoprotein IIb/IIIa antagonists: a meta-analysis of phase III multicenter randomized trials," Circulation, vol. 103, no. 2, pp. 201-206, 2001.
[196] E. S. Tai, D. Collins, S. J. Robins, et al., "The L162V polymorphism at the peroxisome proliferator activated receptor $\alpha$ locus modulates the risk of cardiovascular events associated with insulin resistance and diabetes mellitus: the Veterans Affairs HDL Intervention Trial (VA-HIT)," Atherosclerosis, vol. 187, no. 1, pp. 153-160, 2006.

[197] A. Keech, R. J. Simes, P. Barter, et al., "Effects of long-term fenofibrate therapy on cardiovascular events in 9795 people with type 2 diabetes mellitus (the FIELD study): randomised controlled trial," The Lancet, vol. 366, no. 9500, pp. 18491861, 2005.

[198] B. Staels and J.-C. Fruchart, "Therapeutic roles of peroxisome proliferator-activated receptor agonists," Diabetes, vol. 54, no. 8, pp. 2460-2470, 2005.

[199] F. Blaschke, Y. Takata, E. Caglayan, R. E. Law, and W. A. Hsueh, "Obesity, peroxisome proliferator-activated receptor, and atherosclerosis in type 2 diabetes," Arteriosclerosis, Thrombosis, and Vascular Biology, vol. 26, no. 1, pp. 28-40, 2006.

[200] P. Biswas, L. V. Wilton, and S. A. Shakir, "Troglitazone and liver function abnormalities: lessons from a prescription event monitoring study and spontaneous reporting," Drug Safety, vol. 24, no. 2, pp. 149-154, 2001.

[201] "Troglitazone withdrawn from market," American Journal of Health-System Pharmacy, vol. 57, no. 9, p. 834, 2000.

[202] B. K. Irons, R. S. Greene, T. A. Mazzolini, K. L. Edwards, and R. B. Sleeper, "Implications of rosiglitazone and pioglitazone on cardiovascular risk in patients with type 2 diabetes mellitus," Pharmacotherapy, vol. 26, no. 2, pp. 168-181, 2006.

[203] J. A. Dormandy, B. Charbonnel, D. J. Eckland, et al., "Secondary prevention of macrovascular events in patients with type 2 diabetes in the PROactive Study (PROspective pioglitAzone Clinical Trial in macroVascular Events): a randomised controlled trial," The Lancet, vol. 366, no. 9493, pp. 12791289, 2005.

[204] S. M. Haffner, A. S. Greenberg, W. M. Weston, H. Chen, K. Williams, and M. I. Freed, "Effect of rosiglitazone treatment on nontraditional markers of cardiovascular disease in patients with type 2 diabetes mellitus," Circulation, vol. 106, no. 6, pp. 679-684, 2002.

[205] S. E. Kahn, S. M. Haffner, M. A. Heise, et al., "Glycemic durability of rosiglitazone, metformin, or glyburide monotherapy," The New England Journal of Medicine, vol. 355, no. 23, pp. 2427-2443, 2006.

[206] A. J. Scheen, "DREAM study: prevention of type 2 diabetes with ramipril and/or rosiglitazone in persons with dysglycaemia but no cardiovascular desease," Revue Medicale de Liege, vol. 61, no. 10, pp. 728-732, 2006.

[207] P. D. Home, S. J. Pocock, H. Beck-Nielsen, et al., "Rosiglitazone evaluated for cardiovascular outcomes-an interim analysis," The New England Journal of Medicine, vol. 357, no. 1, pp. 28-38, 2007.

[208] T.-A. Cock, S. M. Houten, and J. Auwerx, "Peroxisome proliferator-activated receptor- $\gamma$ : too much of a good thing causes harm," EMBO Reports, vol. 5, no. 2, pp. 142-147, 2004.

[209] S. M. Rangwala and M. A. Lazar, "The dawn of the SPPARMs?” Science's STKE, vol. 2002, no. 121, p. pe9, 2002.

[210] P. V. Devasthale, S. Chen, Y. Jeon, et al., "Discovery of tertiary aminoacids as dual PPAR $\alpha / \gamma$ agonists-I," Bioorganic \& Medicinal Chemistry Letters, vol. 17, no. 8, pp. 2312-2316, 2007.

[211] P. V. Devasthale, S. Chen, Y. Jeon, et al., "Design and synthesis of $N$-[(4-methoxyphenoxy)carbonyl $]-N-[[4-[2-(5-$ methyl- 2-phenyl-4-oxazolyl)ethoxy]phenyl]methyl]glycine 
[muraglitazar/BMS-298585], a novel peroxisome proliferator-activated receptor $\alpha / \gamma$ dual agonist with efficacious glucose and lipid-lowering activities," Journal of Medicinal Chemistry, vol. 48, no. 6, pp. 2248-2250, 2005.

[212] T. Hatae, M. Wada, C. Yokoyama, M. Shimonishi, and T. Tanabe, "Prostacyclin-dependent apoptosis mediated by PPAR $\delta$," Journal of Biological Chemistry, vol. 276, no. 49, pp. 46260-46267, 2001.

[213] R. Hertz, I. Berman, D. Keppler, and J. Bar-Tana, "Activation of gene transcription by prostacyclin analogues is mediated by the peroxisome-proliferators-activated receptor (PPAR)," European Journal of Biochemistry, vol. 235, no. 1-2, pp. 242247, 1996.

[214] H. Lim and S. K. Dey, "PPAR $\delta$ functions as a prostacyclin receptor in blastocyst implantation," Trends in Endocrinology and Metabolism, vol. 11, no. 4, pp. 137-142, 2000. 


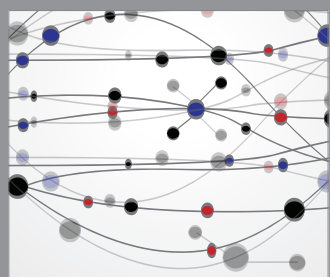

The Scientific World Journal
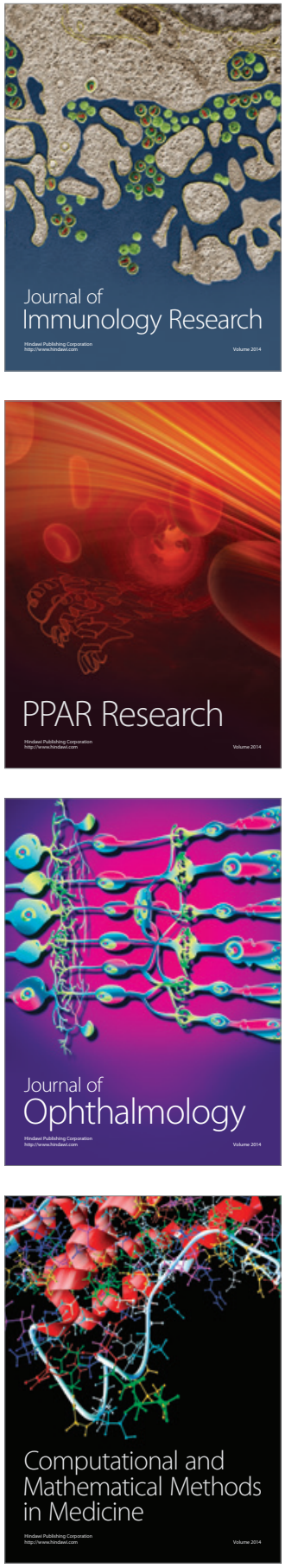

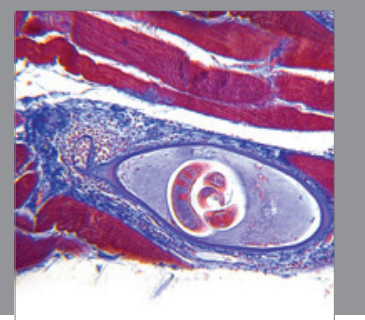

Gastroenterology

Research and Practice
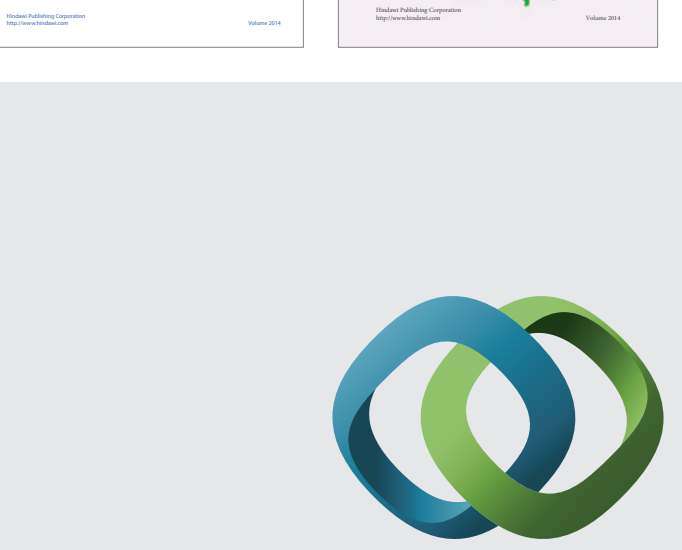

\section{Hindawi}

Submit your manuscripts at

http://www.hindawi.com
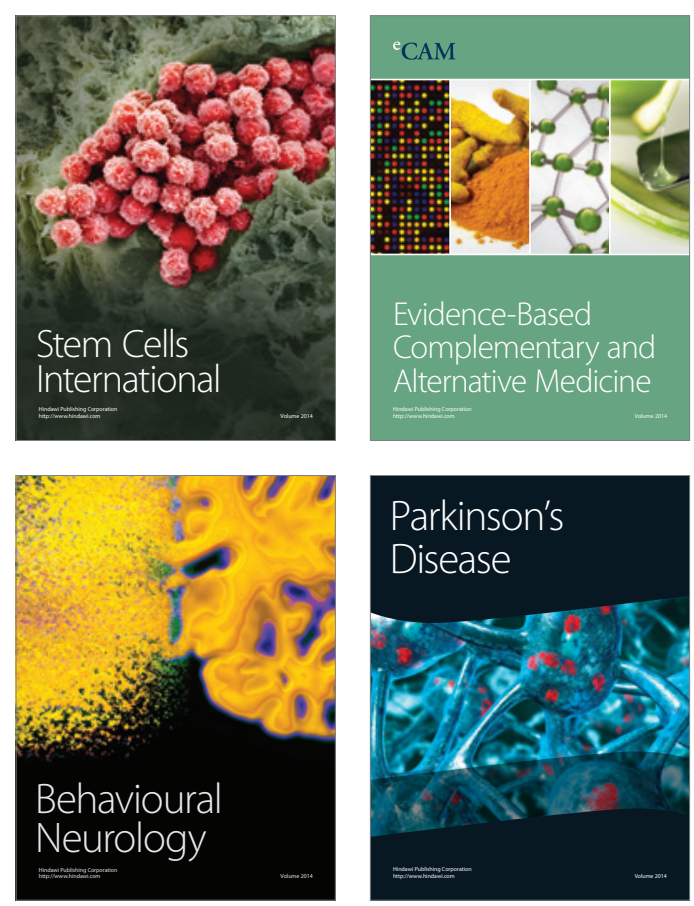

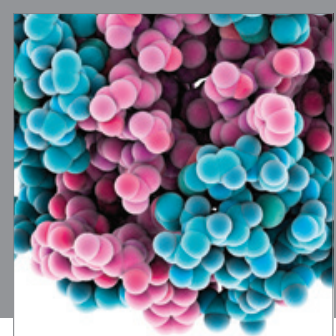

Journal of
Diabetes Research

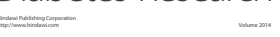

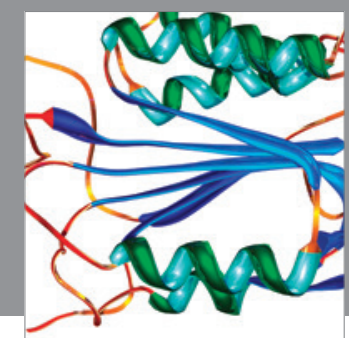

Disease Markers
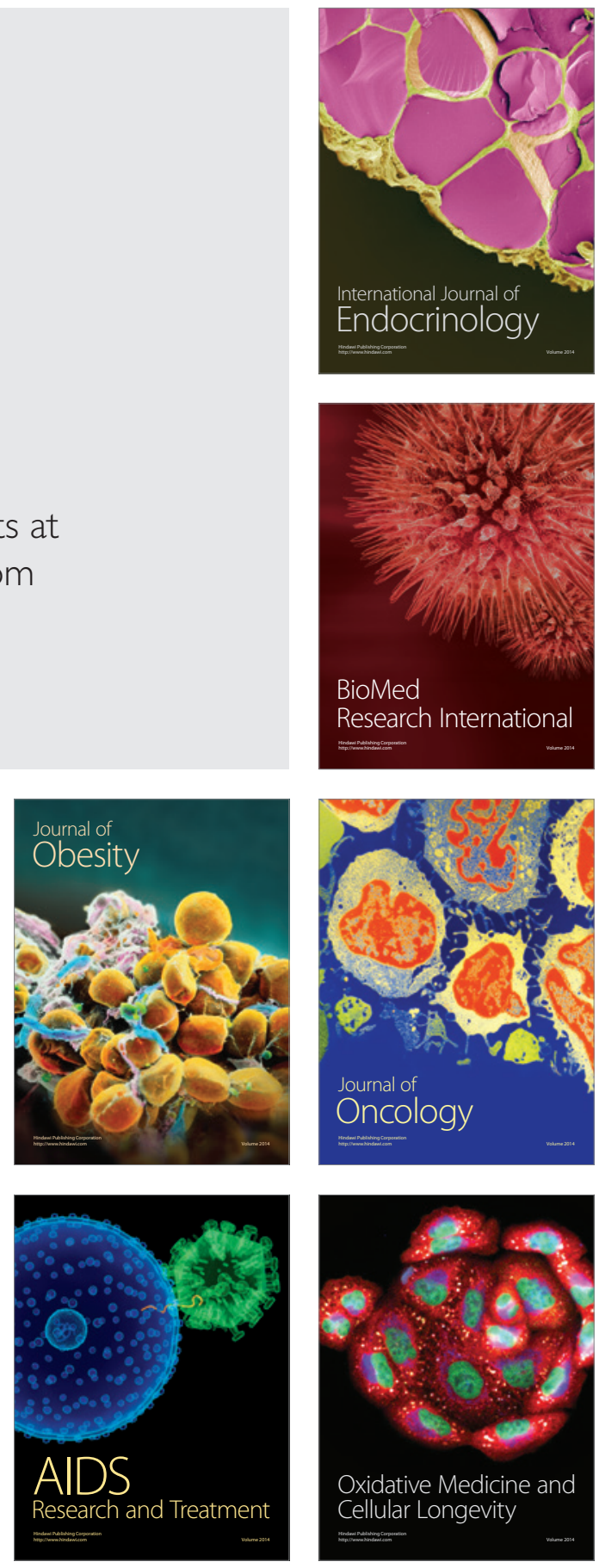